\title{
The unpredictable journeys of spreading, sustaining and scaling healthcare innovations: a scoping review
}

\author{
Élizabeth Côté-Boileau ${ }^{1,2,3,4^{*}}$, Jean-Louis Denis ${ }^{5,6,7}$, Bill Callery ${ }^{8}$ and Meghan Sabean ${ }^{8}$
}

\begin{abstract}
Innovation has the potential to improve the quality of care and health service delivery, but maximising the reach and impact of innovation to achieve large-scale health system transformation remains understudied. Interest is growing in three processes of the innovation journey within health systems, namely the spread, sustainability and scale-up (3S) of innovation. Recent reviews examine what we know about these processes. However, there is little research on how to support and operationalise the 3S. This study aims to improve our understanding of the $3 S$ of healthcare innovations. We focus specifically on the definitions of the $3 \mathrm{~S}$, the mechanisms that underpin them, and the conditions that either enable or limit their potential. We conducted a scoping review, systematically investigating six bibliographic databases to search, screen and select relevant literature on the $3 \mathrm{~S}$ of healthcare innovations. We screened 641 papers, then completed a full-text review of 112 identified as relevant based on title and abstract. A total of 24 papers were retained for analysis. Data were extracted and synthesised through descriptive and inductive thematic analysis. From this, we develop a framework of actionable guidance for health system actors aiming to leverage the 35 of innovation across five key areas of focus, as follows: (1) focus on the why, (2) focus on perceived-value and feasibility, (3) focus on what people do, rather than what they should be doing, (4) focus on creating a dialogue between policy and delivery, and (5) focus on inclusivity and capacity building. While there is no standardised approach to foster the $3 S$ of healthcare innovations, a variety of practical frameworks and tools exist to support stakeholders along this journey.
\end{abstract}

Keywords: Innovation, spread, sustainability and scale-up, definitions, mechanisms, support conditions, large-scale system transformation, quality improvement

\section{Background}

It is difficult to understand how innovations circulate in highly institutionalised and rapidly changing environments such as health systems [1-5]. Health systems in various jurisdictions are slow to adapt, innovate and improve at a sufficient pace [6-8]. According to Health Quality Ontario "... fewer than 40\% of healthcare improvement initiatives successfully transition from adoption to sustained implementation that spreads to more than one area of an organization" ([7], p. 4). This can be challenging to healthcare communities intent on increasing

\footnotetext{
* Correspondence: elizabeth.cote-boileau@usherbrooke.ca

${ }^{1}$ Health Sciences Research, Faculty of Medicine and Health Sciences,

University of Sherbrooke, Quebec, Canada

${ }^{2}$ Charles-Le Moyne - Saguenay-Lac-Saint-Jean Research Center on Health

Innovations, Quebec, Canada

Full list of author information is available at the end of the article
}

the impact of innovations within and beyond jurisdictions $[8,9]$. The innovation journeys that would enable improvement in local settings to expand and bring about large-scale health system transformation remains something of a black box $[10,11]$. A growing body of research in health systems focuses on three specific processes as potential levers to accelerate improvement and innovation, namely the spread, sustainability and scale-up (hereafter referred to as the 3S) of healthcare innovations [12-16].

The literature on the $3 \mathrm{~S}$ of healthcare innovations highlights that these processes unfold along a continuum [17-23], where progress is enabled or challenged by a set of unpredictable dynamics, contextual factors and organisational processes [24-28]. The growing interest in the $3 \mathrm{~S}$ reflects a need to respond to the challenge of increasing the innovative capacities of health systems and 
organisations. However, against the promise of the $3 \mathrm{~S}$ of innovation, scholars stress that innovation is, in effect, a journey, which is unpredictable in nature and involves social, dynamic and non-linear processes [29-38]. Thus, there seems to be an emerging tension in the literature between, on the one hand, the idea that the journeys innovation takes through the $3 \mathrm{~S}$ can be grasped, supported and achieved by means of a structured approach, and on the other, the idea that neither the journeys of innovation nor their effects can be predicted. In order to reconcile this tension, we consider that the social, dynamic and iterative characteristics of innovation journeys are themselves the structuring pillars of innovations. Hence, while paying attention to the social dynamics that underlie innovation journeys through the $3 \mathrm{~S}$ may not enable us to predict their course or effects, it may bring us closer to discovering the sources of significant changes that appear along the way.

While the structural changes commonly used in healthcare improvement efforts may help create a more receptive context for innovation, they do not appear sufficient to foster the $3 \mathrm{~S}$ of healthcare innovations and achieve system transformation [39-41]. Large structural reorganisations generally fail to overcome the change-resistant nature of healthcare systems with regards to lasting improvement [42]. Other levers are needed to accelerate uptake of local innovations more systematically [40, 43-50]. These include engagement of front-line managers and providers in a culture of improvement, a focus on population needs, supportive policies and incentives, investment in organisational capacity, participation of patients and citizens, and evidence-informed decision-making [51-54].

This review aims to consolidate the evidence on the $3 \mathrm{~S}$ of healthcare innovation to better understand how they work and the mechanisms and contextual conditions that enable complex health systems and organisations to increase uptake of innovations.

\section{The legacy of the diffusion of innovation model}

Everett Rogers' seminal research on the diffusion of innovations model (DIM) moved the field from technological determinism (i.e. improvements will inevitably be adopted) to a focus on social dynamics (i.e. social factors determine whether and how an improvement will be adopted) [16, 20-22, 55]. The innovation journey according to Rogers is a process of social exchange and construction in which meanings and values attributed to the innovation take form [56]. His work illustrates that it is not just the properties (relative advantage, compatibility, complexity, trialability and observability) of innovations that determine their diffusion $[36,56]$, but rather an aggregate set of factors associated with social relations and communication across networks [57, 58].
These include government regulations, social values promoted by various actors and human interactions around a given innovation $[22,59]$. Indeed, the properties of an innovation will not have the same meaning and value for all actors within a given context, and communication among various individuals and groups within and across contexts influence the acceptability and dissemination of the innovation [59].

The DIM helps to understand the dynamics that take place in centralised diffusion systems as well as decentralised systems that recognise the agency of users in shaping an innovation [58]. However, the DIM does not focus on the mechanisms and enabling conditions for moving innovations from local to large-scale uptake within complex and highly institutionalised sectors such as healthcare. This paper aims to address this gap, in part by looking at the $3 \mathrm{~S}$ of healthcare innovations within Rogers' DIM perspective on the innovation journey.

\section{Methods \\ Scoping review}

A scoping review of the literature was undertaken between October 2016 and April 2017, commissioned by the Canadian Foundation for Healthcare Improvement (CFHI). The central research question was: How to facilitate the $3 \mathrm{~S}$ processes of healthcare innovations? Booth's five-stage process for scoping reviews [60] was employed, involving (1) an exploratory scoping search of existing reviews to get a sense of the volume and scope of available literature on the research topic in order to identify relevant databases and key search terms for the search strategy, (2) a search for relevant peer-reviewed articles and grey literature papers in these databases, using key search terms (both free-text and thesaurus terms), (3) a search for additional relevant articles by screening the bibliographies (reference lists) of all papers, (4) revision and modification of the initial search strategy to ensure that we included all articles potentially relevant to the research question, and (5) extraction, analysis and recording of data from all articles in the form of summary tables.

\section{Search strategy}

We started by exploring 48 prior studies to develop our search strategy. We then used three search engines (EBSCOhost, ERIC, Google Scholar) and seven electronic databases (CINHAL, Academic Search Complete, Business Complete Source, PsycINFO, SocINDEX, MEDLINE, EconLit) to comprehensively search for articles, using the following key search terms: How to Spread OR How to Sustain* OR How to Scale AND Innov* AND health OR healthcare OR health organization* OR health system*. We identified 641 potentially relevant papers from grey 
and peer-review literature for the review. A two-stage screening process was used. The first stage consisted in reviewing articles by title and abstract, which resulted in 112 articles meriting further review. Papers were retained for inclusion if (1) abstracts included the word(s) spread* AND/OR sustain* AND/OR scale*, (2) papers were specific to the healthcare domain, (3) papers provided conceptual and/or empirical guidance on how to facilitate the $3 \mathrm{~S}$ processes of healthcare innovation, and (4) papers represented OECD countries. A total of 18 papers met these criteria and were retained. Screening the bibliographies of these papers and hand searching and verification identified 26 additional papers that went on to full-text review, of which 7 met the above criteria and were retained, bringing us to a total of 25 articles for analysis. Finally, the documentation stage involved extracting, analyzing and summarising the following data from the 24 papers included in the review:

1) Authors and title

2) Research question/aim

3) Methodological design

4) Main process(es)

5) Definitions

6) Mechanisms

7) Enabling and limiting factors

\section{Data analysis}

We used a two-phase analytical approach to extract and synthesise data from retained papers. First, a descriptive analysis was undertaken to categorise papers according to (1) grey literature or peer-reviewed publication status, (2) the $3 \mathrm{~S}$ process(es) addressed and (3) their jurisdiction of publication. Second, we conducted a thematic analysis of the data. Three analytical themes were selected by the CFHI based on their organisational needs and priorities, as follows: (1) 3S definitions, (2) 3S mechanisms and (3) conditions that enable or limit the potential for $3 \mathrm{~S}$ (Table 1). We should emphasise that, while the definition of 'mechanisms' used in this study is supported by Normalisation Process Theory (NPT), NPT was not used as a theoretical lens to extract, analyse and record data specific to the $3 \mathrm{~S}$ mechanisms. NPT is a sociological approach developed to understand the dynamics of integrating new technologies and innovations, particularly in healthcare contexts; in the present paper, we use NPT to add conceptual traction to our efforts to uncover the mechanisms involved in the $3 \mathrm{~S}$ of healthcare innovations.

Both the descriptive and thematic analyses were performed by a single investigator and were validated through peer-review by stakeholders at CFHI. Following each of three review cycles (submitted December 16th, 2016, February 28th, 2017, and July 19th, 2017), the research team revised and refined the outcomes of the scoping review according to feedback provided by CFHI stakeholders. While it was not among the initial study objectives, recurrent insights emerging from analysis of the data allowed us to inductively identify five key learnings on $3 \mathrm{~S}$ from which a framework of actionable guidance was developed and submitted to CFHI in the form of a research report (October 12th, 2017). CFHI then created a task force, including the research team and CFHI senior directors, improvement leads and faculty leads, to provide feedback on the framework, which saw multiple iterations before consensus was reached on its final form.

\section{Results}

\section{Scoping review}

Scoping reviews are useful to answer broad research questions, drawing on a comprehensive literature review to explore the breath of available data produced over a specified time period on a given topic [60]. We performed a scoping review to explore what is known about how to spread, sustain and scale innovations in healthcare. The search and selection process illustrated in Fig. 1 resulted in the inclusion of 24 papers. Of the 24, 15 were peer-reviewed articles and 9 were grey literature publications. The study designs of the peer-reviewed papers included systematic reviews $(n=3)$, case studies $(n=3)$, scoping reviews $(n=2)$, narrative review $(n=1)$, qualitative grounded theory $(n=1)$, longitudinal ethnography $(n=1)$, Delphi technique $(n=1)$ and others $(n=3)$. Most of the scientific and grey literature was informed by sociological, organisational and health sciences disciplines. Overall, the literature mainly focussed on the scale of healthcare innovations $(n=7)$, their sustainability $(n=4)$, spread $(n=4)$, or spread and scale $(n=4)$, or spread and sustainability $(n=4)$, with only one paper addressing all $3 \mathrm{~S}$ components. In terms of jurisdiction,

Table 1 Description of themes included in the thematic analysis

\begin{tabular}{ll}
\hline Theme & Description \\
\hline $\begin{array}{l}\text { Definitions } \\
\text { Mechanisms }\end{array}$ & $\begin{array}{l}\text { Statement of the meaning of a word or concept } \\
\text { Coherence, cognitive participation, collective action, } \\
\text { reflexive monitoring through which human agency is } \\
\text { expressed [61] }\end{array}$ \\
$\begin{array}{l}\text { Internal or external factors that enable or limit the } \\
\text { potential of an organisational process [62] }\end{array}$ \\
\hline
\end{tabular}




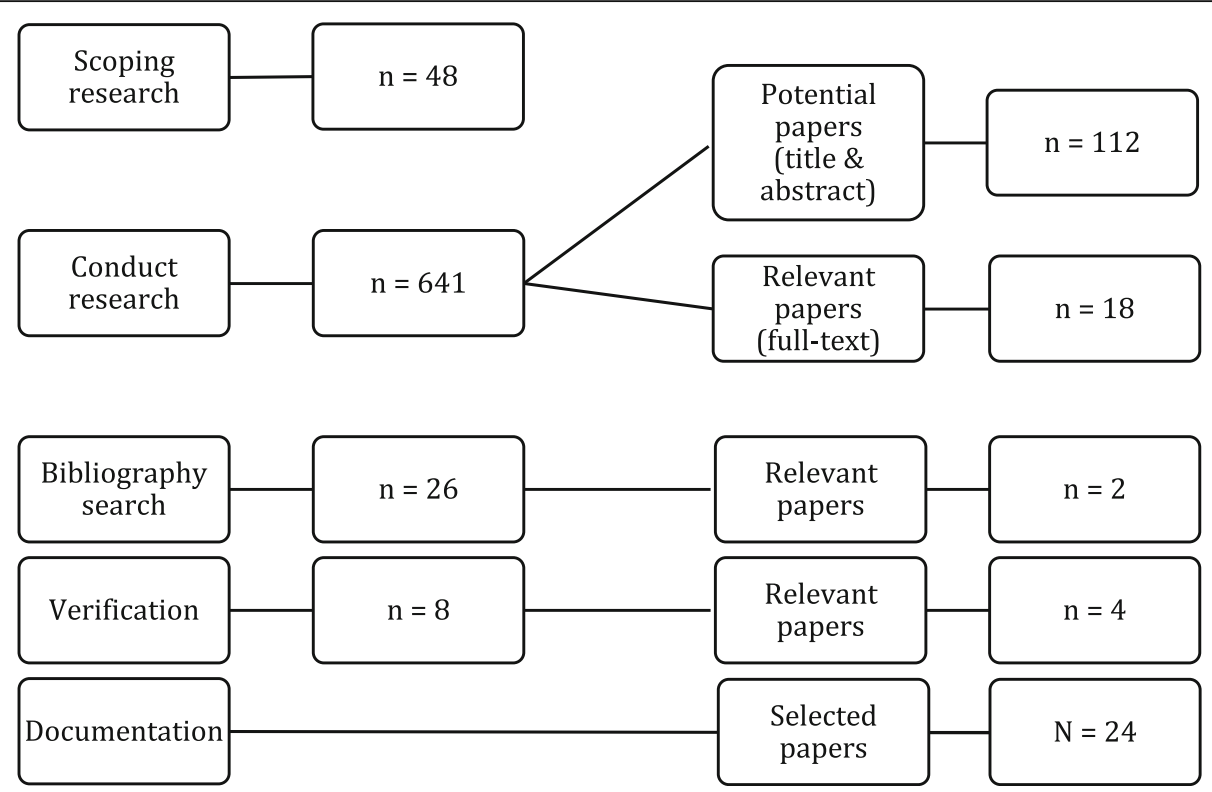

Fig. 1 Scoping review search process flow chart

most studies were conducted in the United Kingdom $(n=10)$, followed by Australia $(n=4)$, Canada $(n=4)$, the United States $(n=3)$, New Zealand $(n=1)$, the Netherlands $(n=1)$ and Kenya $(n=1)$.

\section{Descriptive analysis}

Descriptive analysis aimed to categorise peer-reviewed articles $(n=15)$ and grey-literature publications $(n=9)$ included in the final selection. Tables 2 and 3 present the data extracted from peer-reviewed articles and greyliterature publications, respectively.

\section{Thematic analysis}

\section{Definitions}

Our review shows that there are no standardised definitions for the $3 \mathrm{~S}$ of healthcare innovations. Some authors use the terms spread and sustainability, or spread and scale-up, interchangeably $[24,78]$. The $3 S$ can be characterised as social, dynamic, non-linear and unpredictable processes [9, 12, 24, 25, 64], and various sub-concepts associated with $3 \mathrm{~S}$ add to both the complexity and richness of these processes (Table 4).

Spread is commonly defined as both passive and deliberate efforts to communicate and implement an innovation, and usually involves adapting an innovation to a new setting $[13,67,87]$. Although the dualistic nature of 'passive and deliberate' efforts can give rise to conceptual tensions, many scholars argue that these opposing characteristics emerge along a continuum from diffusion to dissemination of innovations. Along that continuum, diffusion would be associated with passive efforts, and dissemination would refer to more deliberate actions. While some authors describe spread as iterative, we found no studies that established a sequential relationship or degree of iteration between diffusion, dissemination and adoption through the spread process $[9,12,13,15]$.

Sustainability is commonly defined as what happens when an innovation becomes routinised within an organisation or other setting. Sustainability and implementation are closely related; the primary difference is that implementation is time-limited, while sustainability occurs over an undefined time, allowing actors to continuously learn and reflect on their experimentation [16, 88-90].

Scale-up commonly refers to the process in which the coverage and impact of an innovation are expanded to reach all potential beneficiaries. In that sense, what would most significantly distinguish spread from scale is not the processes involved, but the goal. As mentioned earlier, spread aims to communicate and implement an innovation, and usually involves adapting an innovation to a new setting, while scale focuses more on expanding the range of people who would benefit from a given innovation. It mostly consists of broadening innovations from local settings to wider jurisdictional or policy contexts. The concept of scalability [84], expandability [70], fidelity [77] and replicability [85, 86] are associated with scaling up an innovation.

The common definitions of these terms allude to the importance of balancing preservation of the core elements of an innovation (fidelity) with contextual adjustments (adaptability). Evidence on the scale-up of healthcare innovations and large-scale transformation also emphasises the need to balance 'hard' assets (e.g. 


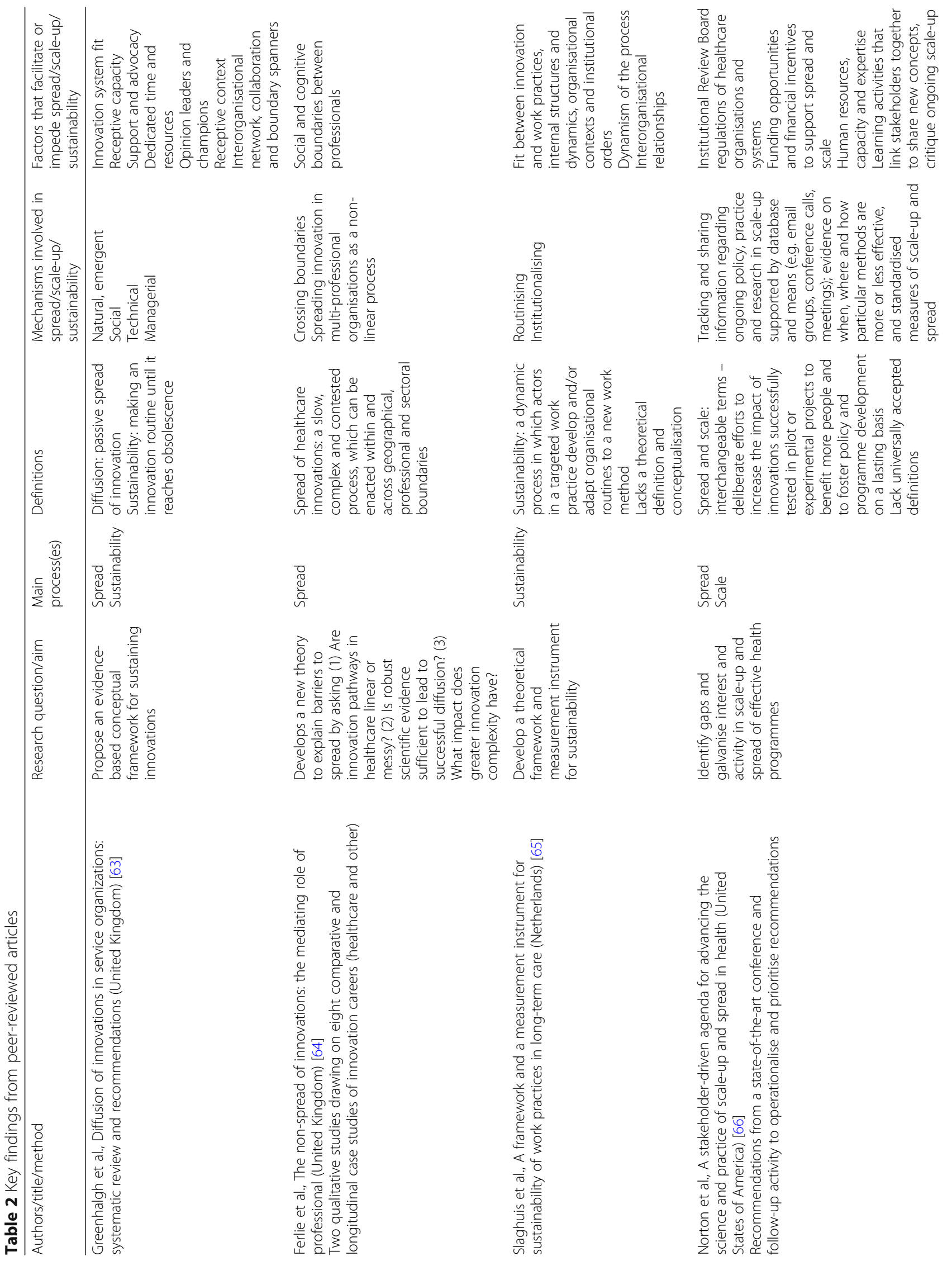




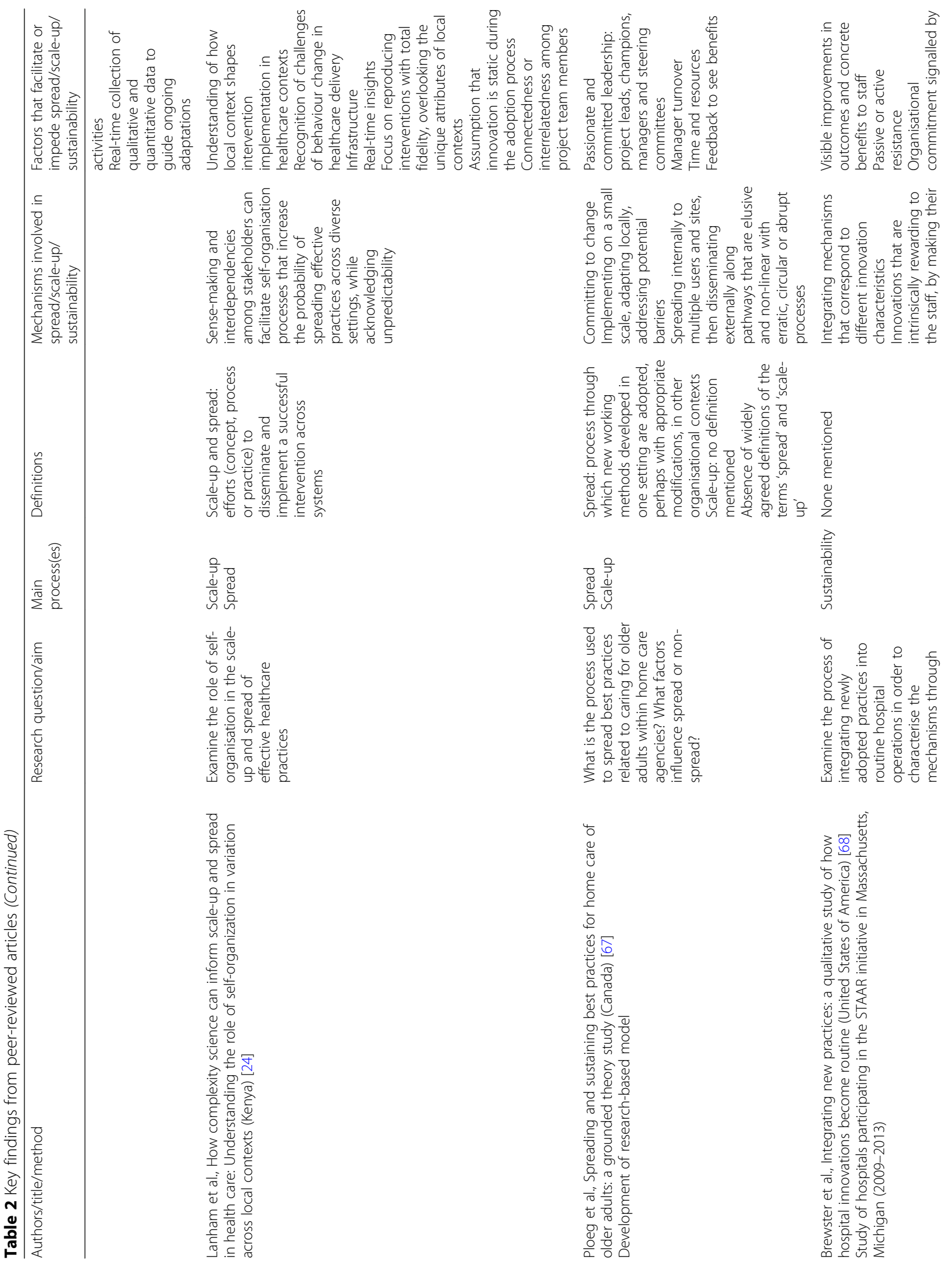




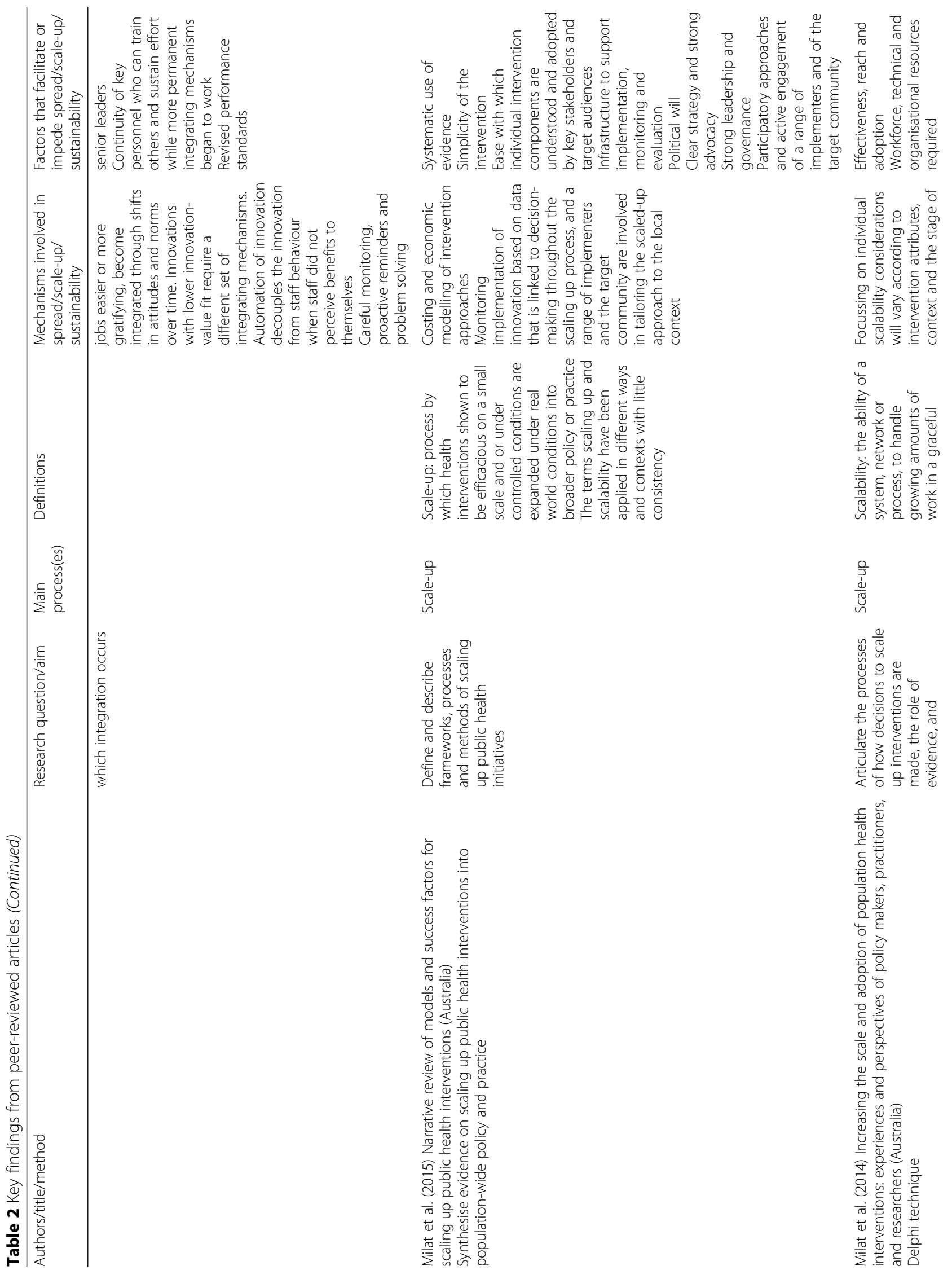




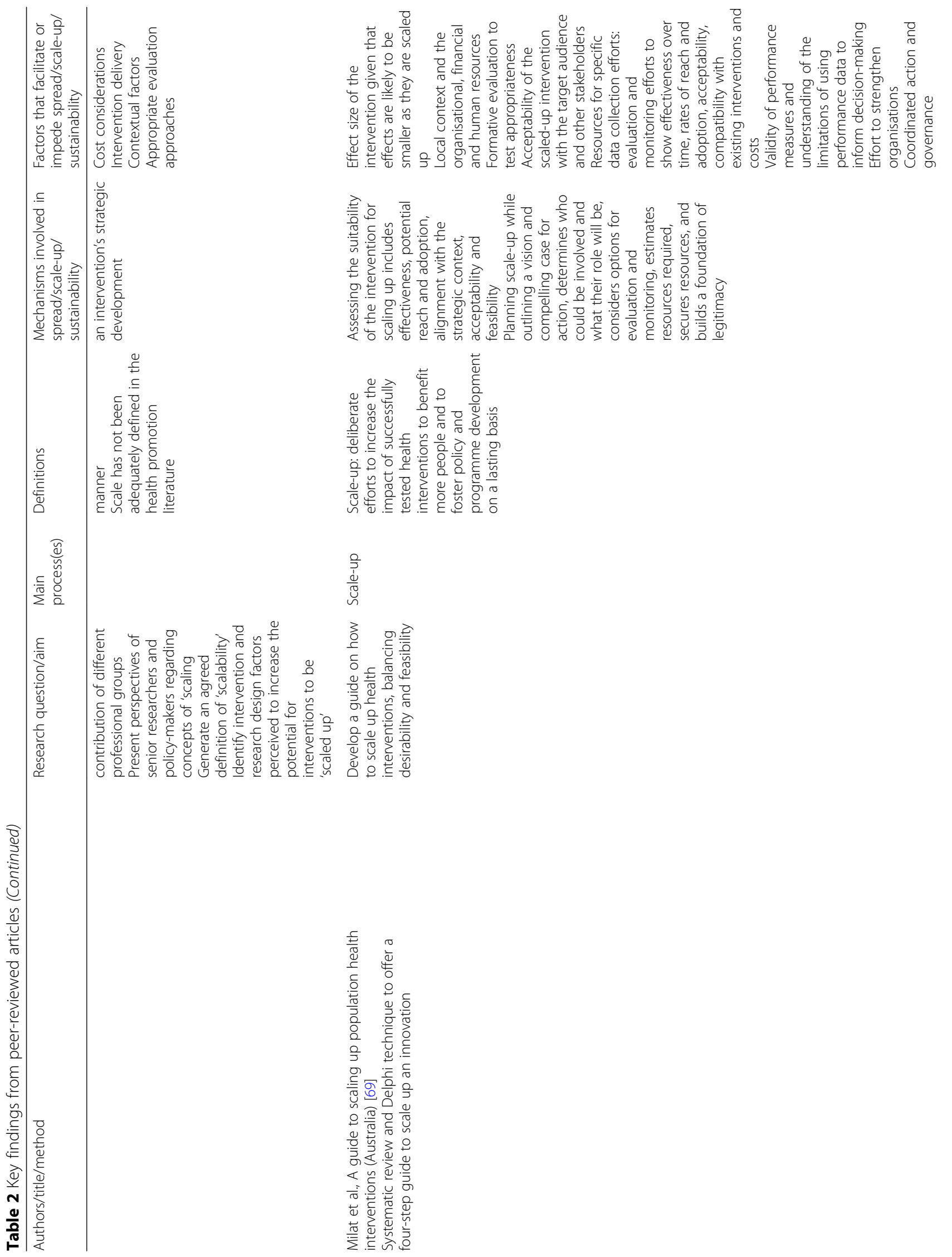









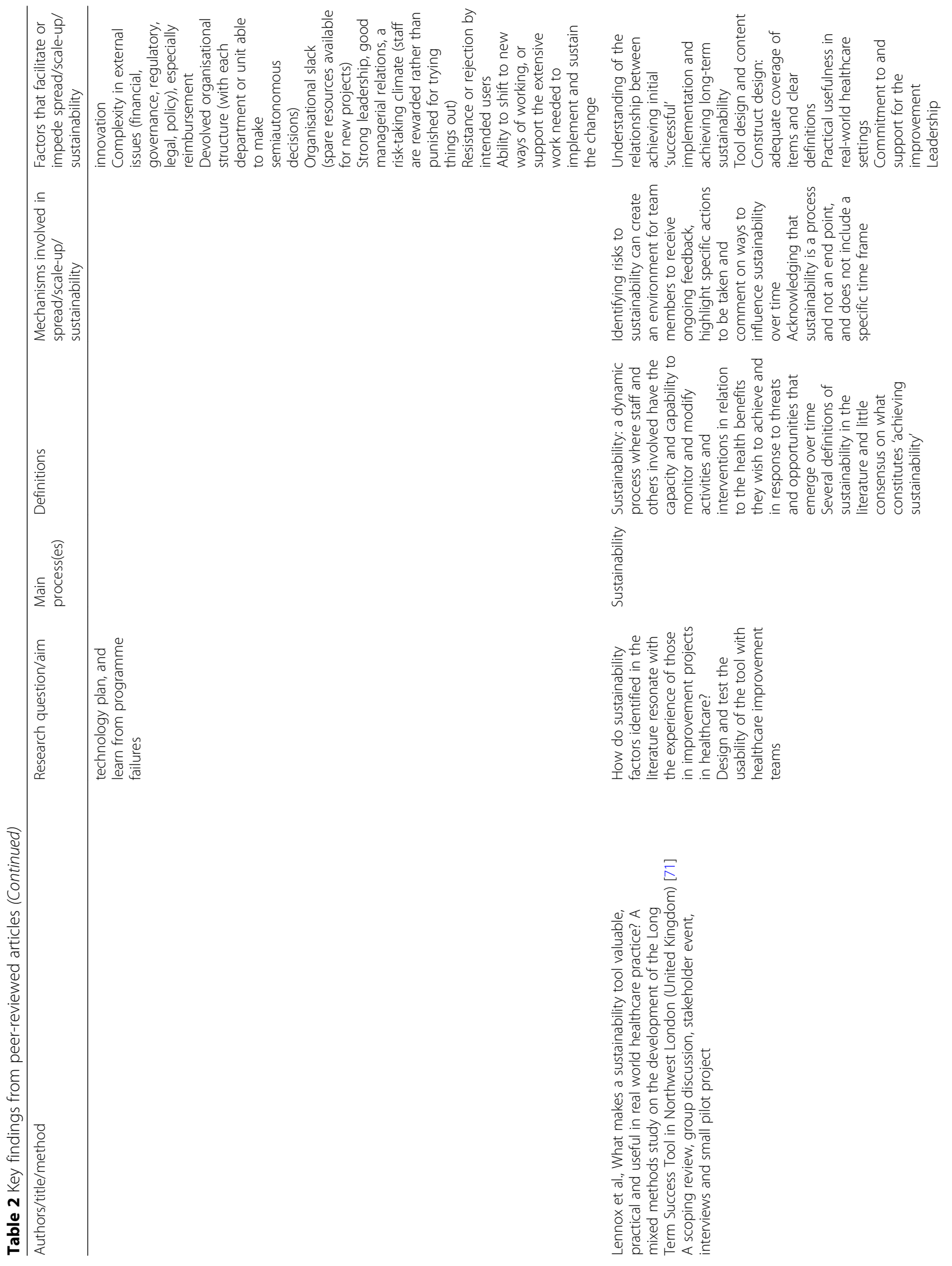




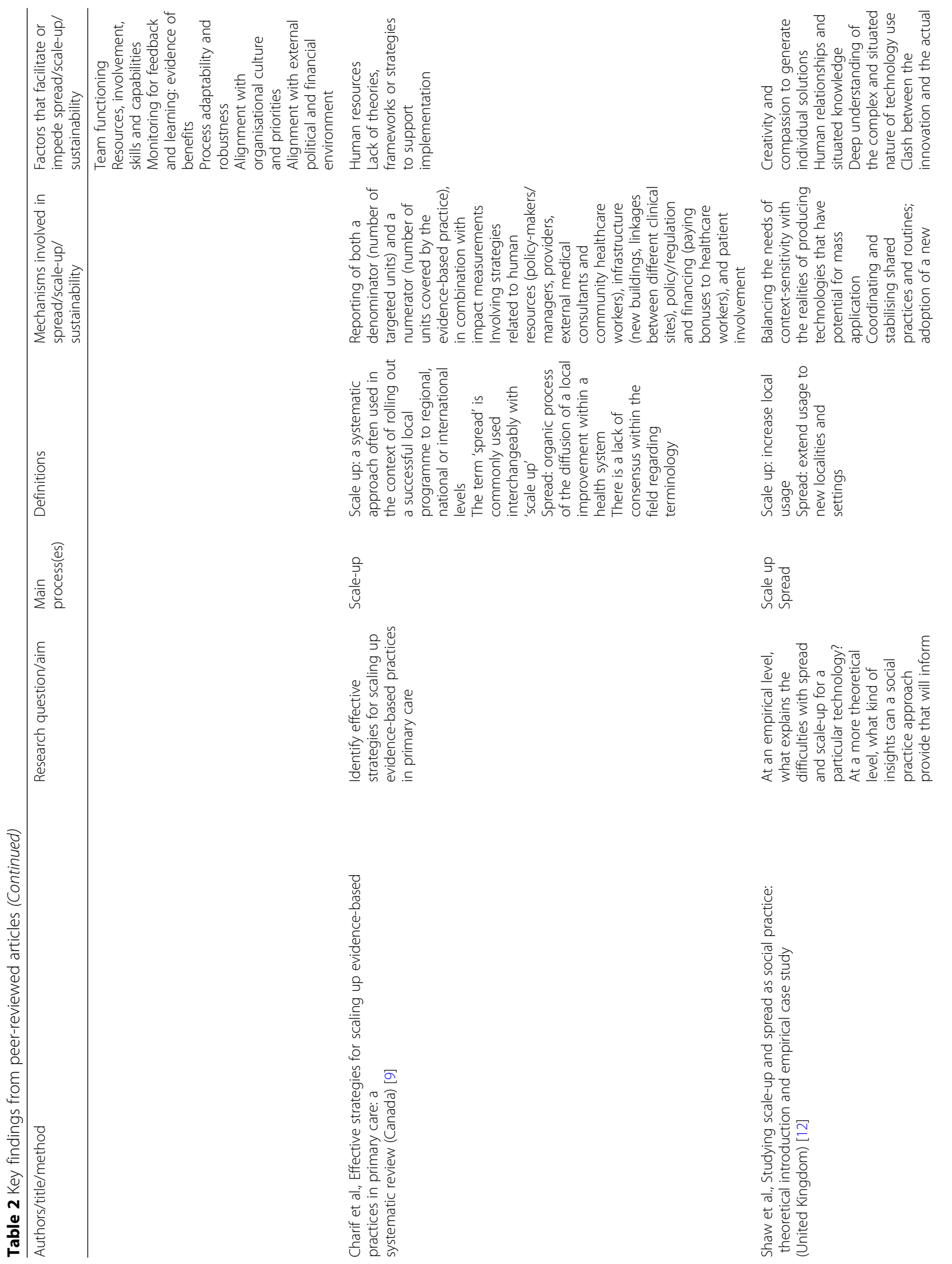




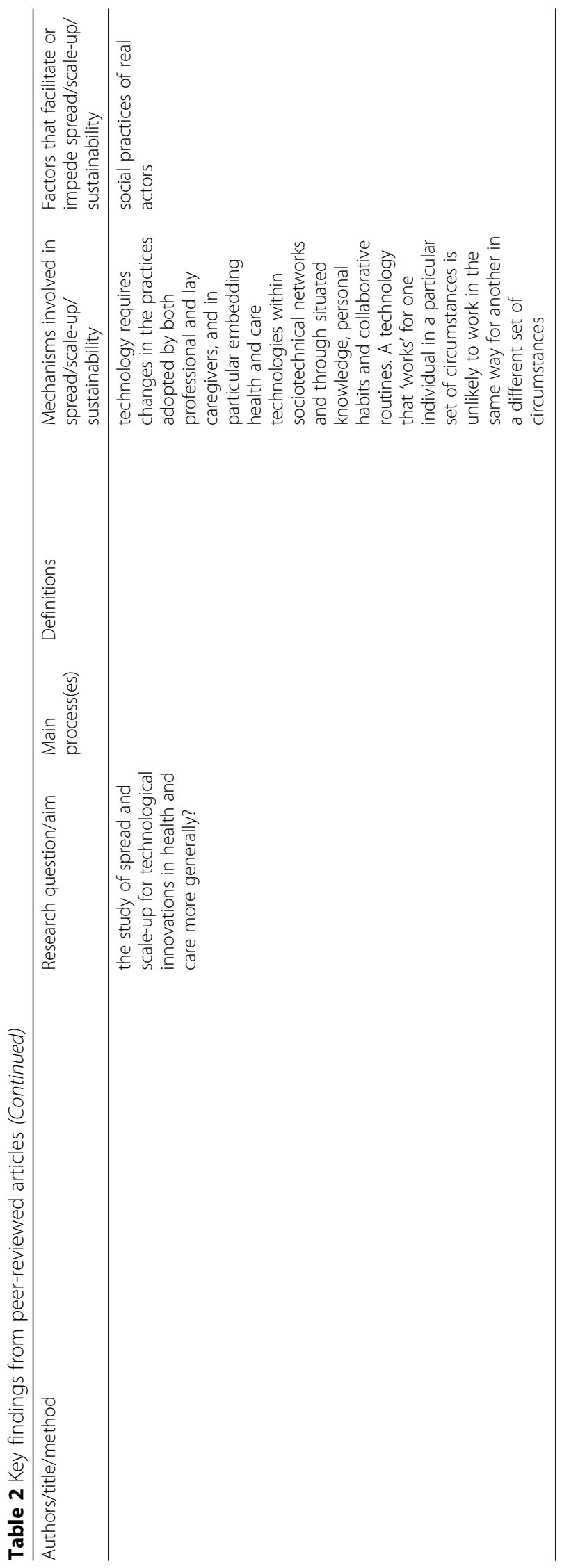




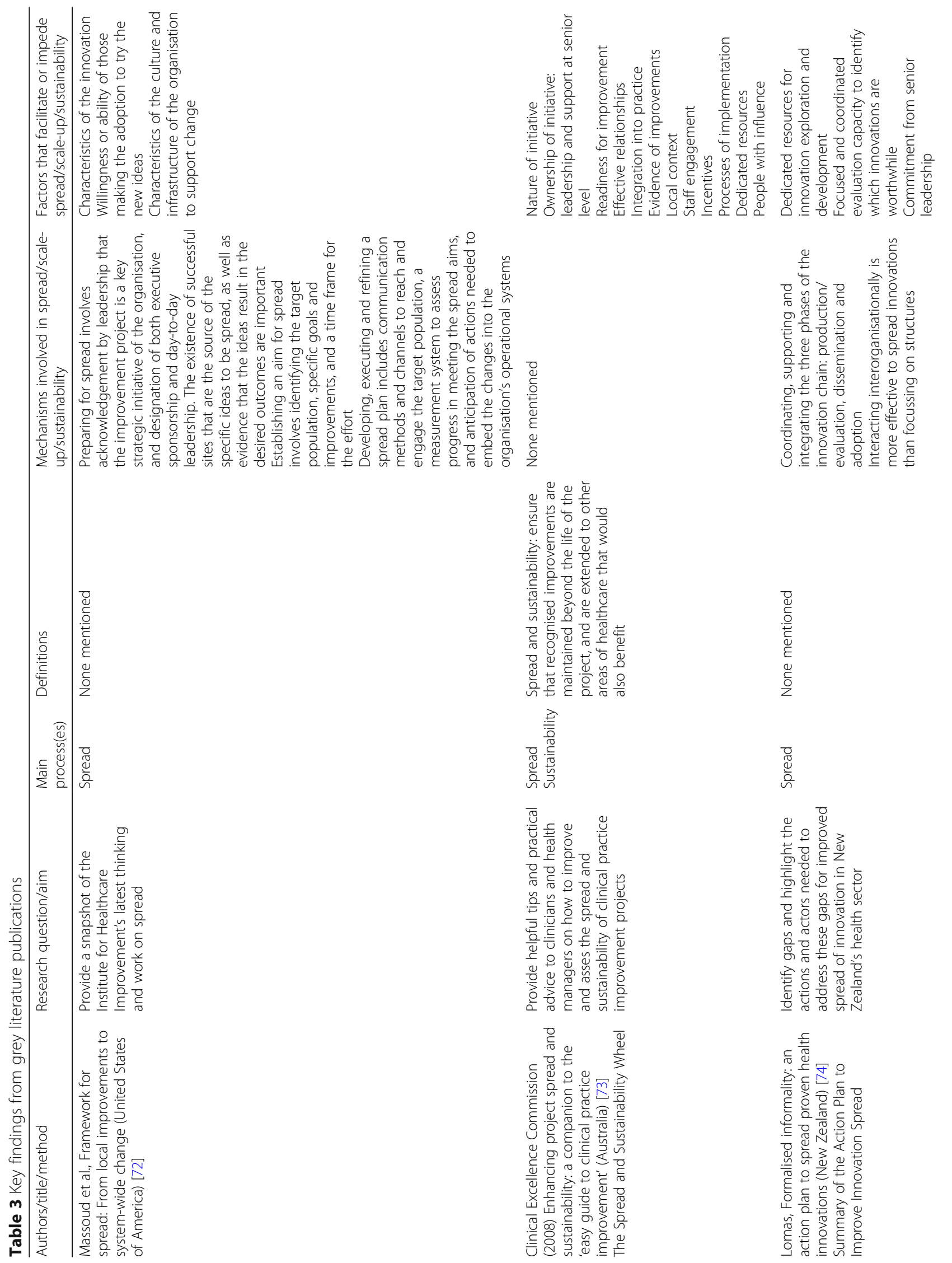




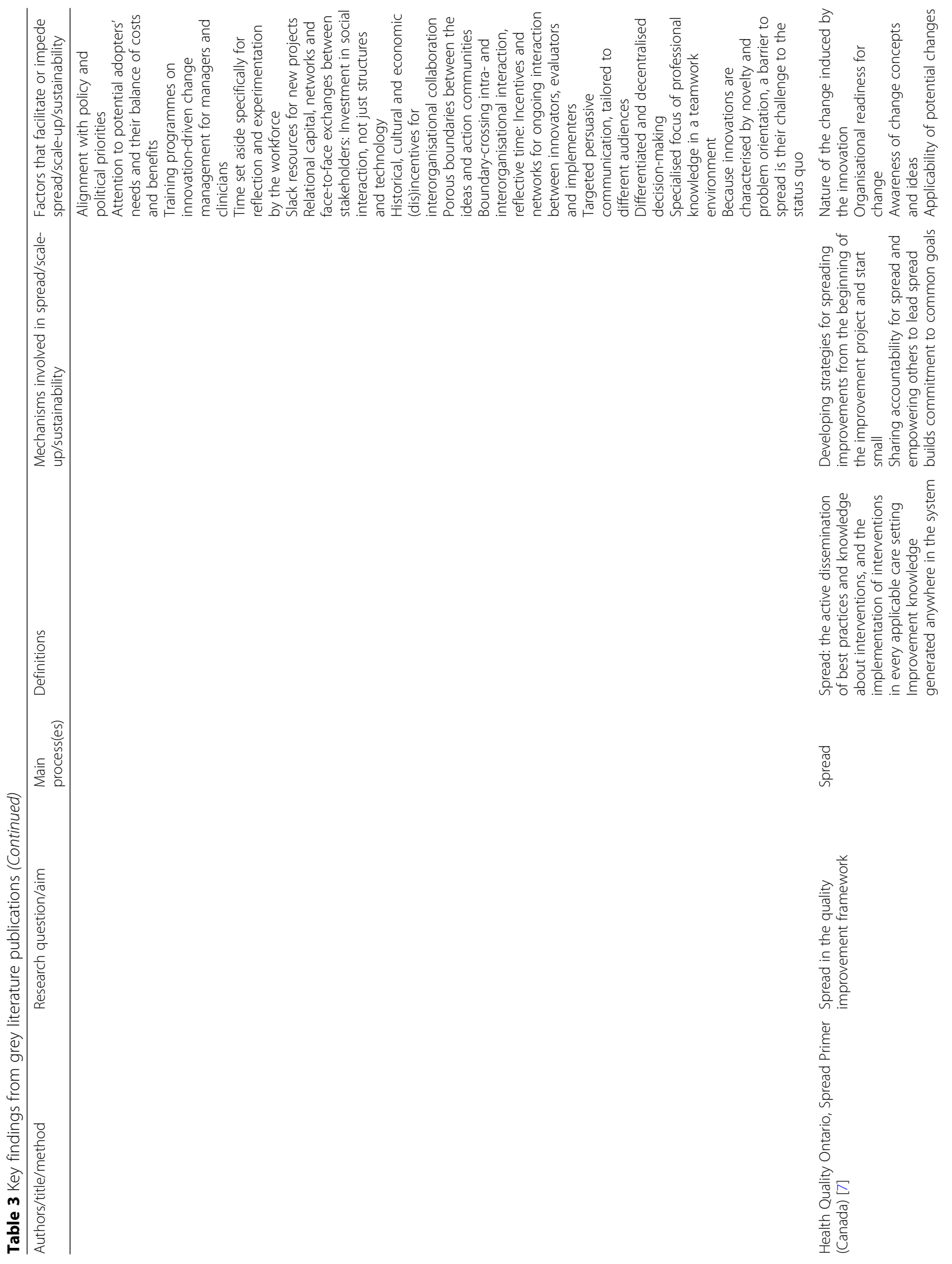




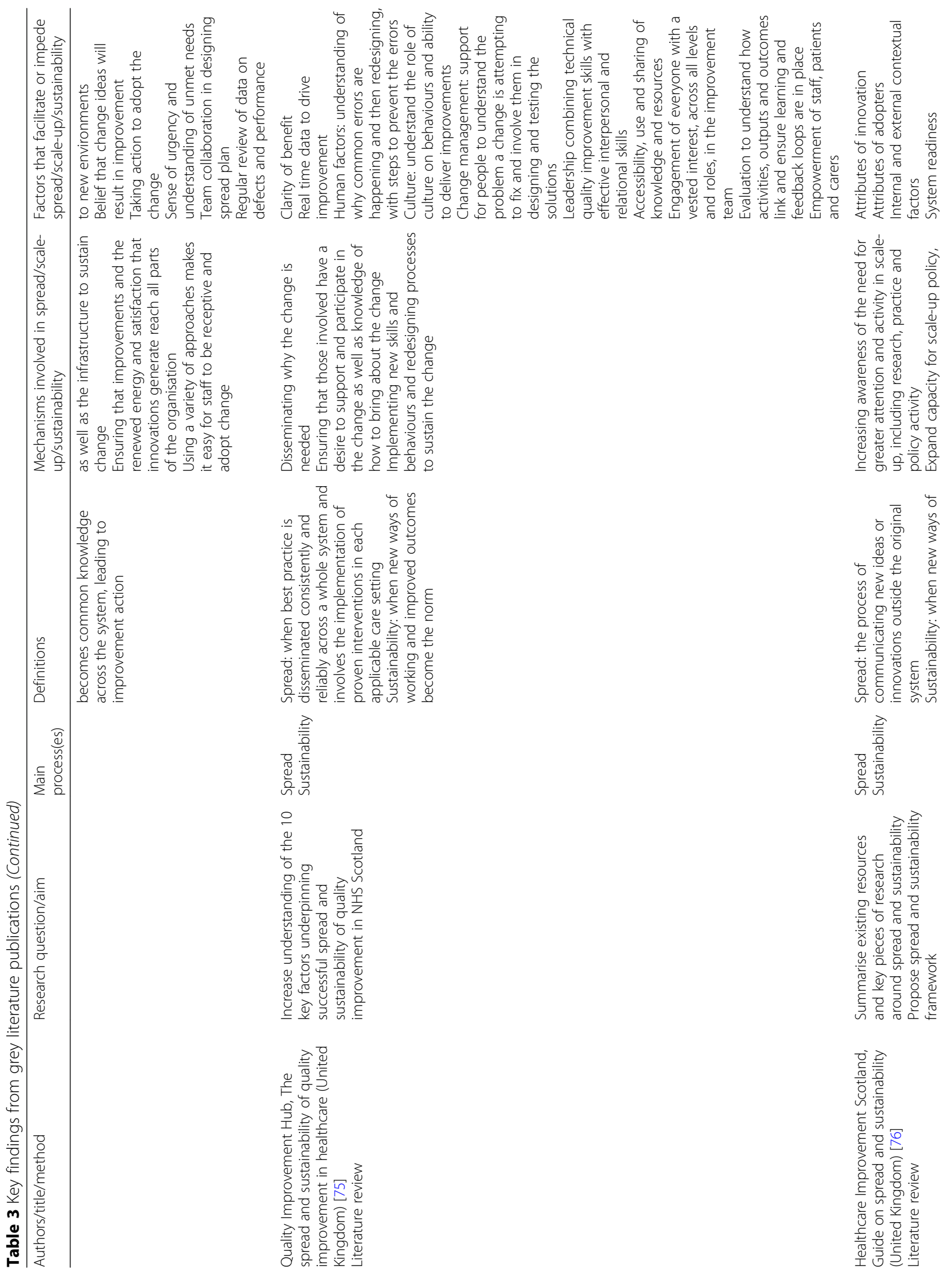




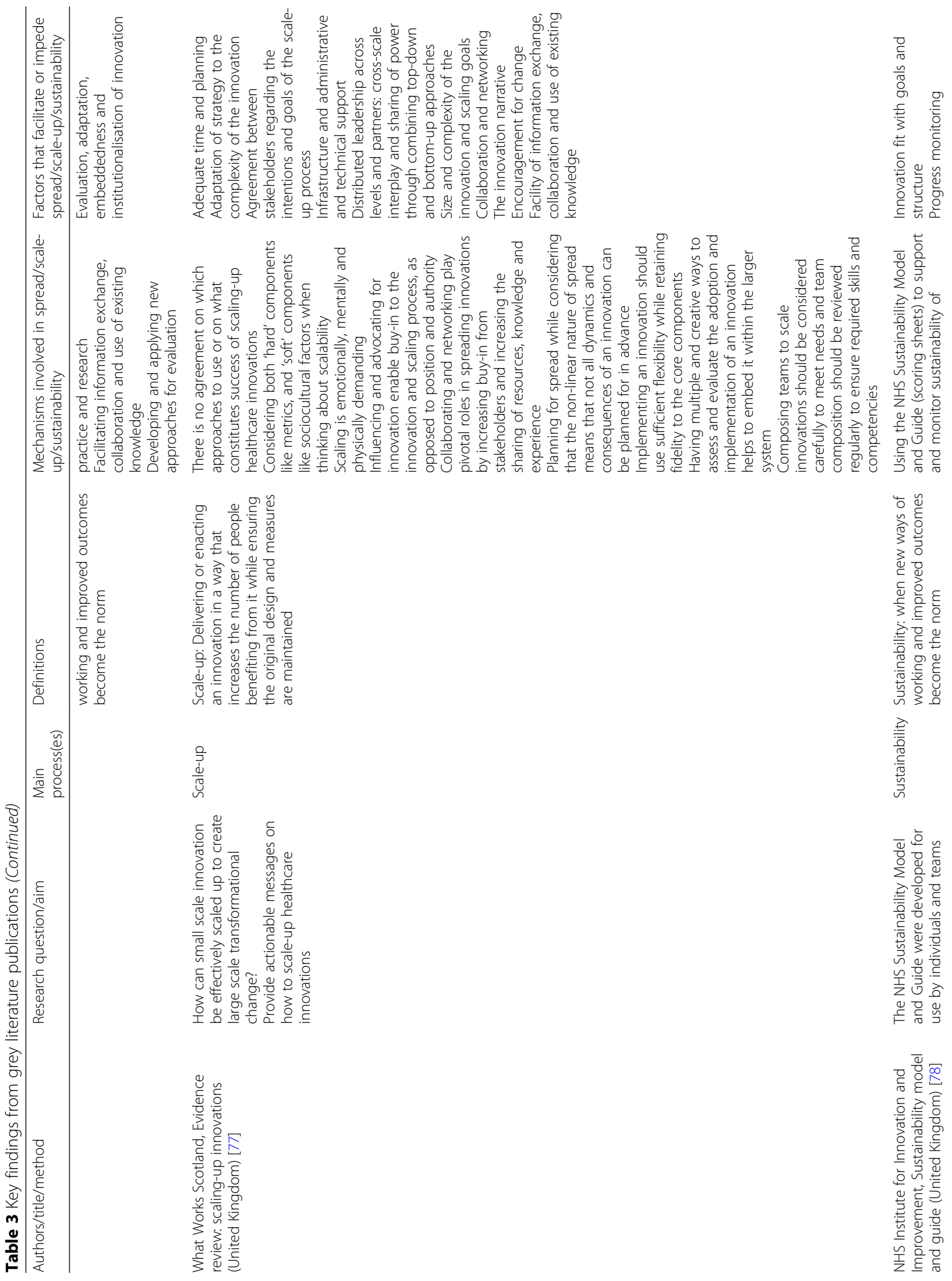




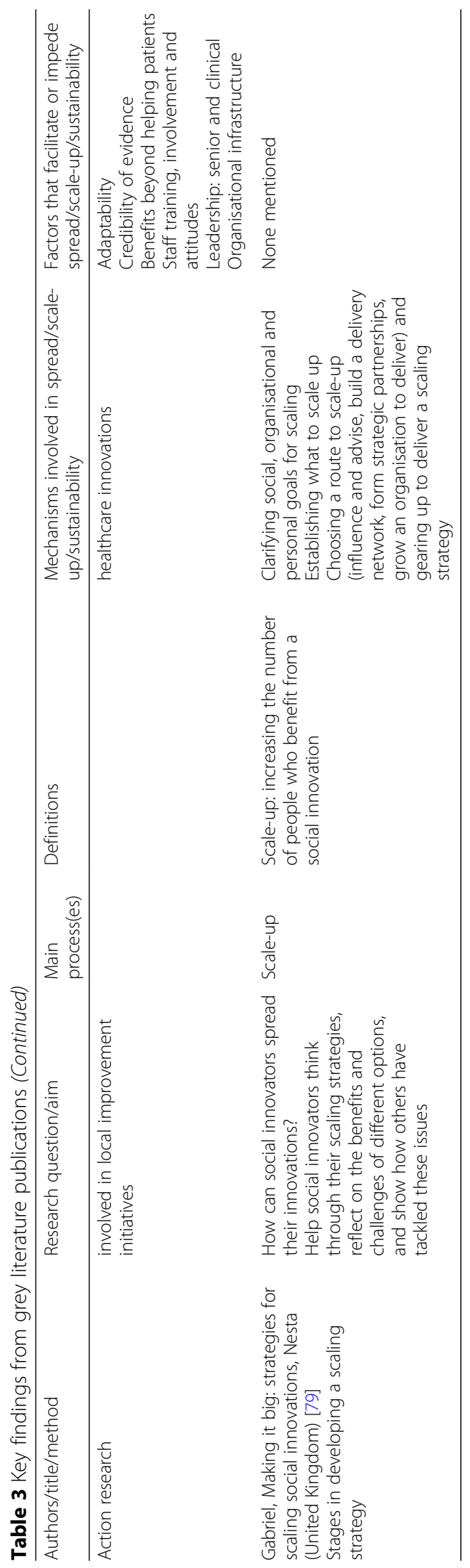


Table 4 Definitions

\begin{tabular}{lll}
\hline Concepts & Definitions & Associated sub-concepts \\
\hline Spread & The process through which new working methods developed in one setting & Dissemination [63] \\
& $\begin{array}{l}\text { are adopted, perhaps with appropriate modifications, in other organisational } \\
\text { contexts [25, 67] }\end{array}$ & Diffusion [59, 63] \\
Sustainability & $\begin{array}{l}\text { The process through which new working methods, performance enhancements } \\
\text { and continuous improvements are maintained for a period appropriate to a }\end{array}$ & Adoption [81] \\
& given context [25] & \\
The ambition or process of expanding the coverage of health interventions, but & Scalability [84] \\
Scale & can also refer to increasing the financial, human and capital resources required & Expandability [70] \\
& to expand coverage [83] & Fidelity [77] \\
& & Replication [85, 86] \\
\hline
\end{tabular}

performance metrics) and 'soft' assets (e.g. history, relational background, existing partnerships within a given organisational setting) $[9,24,66,77]$. The successful scaling of healthcare innovations seems to require a balanced and comprehensive set of resources, including financial, technical, relational and political assets. Building on a comprehensive set of capacities may lead to a more successful and sustainable scaling process.

What remains less clear in the definition of $3 \mathrm{~S}$ is the role of policy environments and governance capacities in shaping the innovation journey within and across healthcare systems. While several frameworks acknowledge the importance of policy, political context and organisational structure to the progress of innovation in healthcare settings, little is known about the relation between governance capacities, which involve the capacity to implement and monitor policies, and the success of the 3S. Although they are generally described as processes on a continuum with well-delineated phases, the $3 \mathrm{~S}$ may refer to innovation journeys that reflect the uncertain and contextualised nature of innovations, as well as the iterative and overlapping nature of the $3 \mathrm{~S}$.

\section{Mechanisms}

There are no standardised mechanisms to support the $3 S$ of innovation $[66,91]$, though many healthcare institutions and agencies have attempted to develop plausible insights into how they might be supported [7, 73-75, 77-79, 92-94]. While the grey literature provides various frameworks and tools, the scientific literature suggests that there is no 'one size fits all' approach $[1,13$, $25,87]$. Rather, the $3 S$ processes overlap in their operational application, and the mechanisms behind $3 \mathrm{~S}$ are often described as cutting across these three processes. Based on findings from our scoping review, we argue that $3 \mathrm{~S}$ mechanisms be categorised along four aspects of the innovation journey, namely substance (innovation), processes, stakeholders and context (Fig. 2).

Substance As argued by Rogers [57, 58, 59], characteristics of the substance of an innovation influence $3 \mathrm{~S}$. While the substance of an innovation is variable, the innovation results from successful exploitation of people's ideas and capacities [91]. Given the diversity of actors, ideas and capacities in healthcare systems and organisations, the source of innovation is dynamic [95]. While healthcare has what Berwick calls a 'pro-innovation bias' $[96,97]$, healthcare innovations are not always appropriate, valuable or feasible. Therefore, actors must engage in a serious assessment of the relative advantage of the innovation not only by patients, but also by providers, managers, policy-makers and sometimes third parties. If the innovation is viewed favourably, the next challenge for its $3 \mathrm{~S}$ is balancing fidelity and adaptability [25, 98]. This paradox arises from a need for continuous contextual adaptation, without crossing the line beyond which the innovation becomes 'too different' to deliver the expected improvement $[71,99,100]$. The literature suggests paying attention to the substance of the innovation, while monitoring outcomes to be sure that $3 \mathrm{~S}$ generates continuous improvement towards the initial objective [88].

Processes Processes show up in the dynamics underpinning a phenomenon such as the 3S [101-103]. The literature identifies some specific processes associated with spread and sustainability (e.g. diffusing, disseminating, adapting, adopting, implementing), but these are less clear for scale-up $[66,89,104]$. There is a need to identify and understand the cumulative effect of processes associated with sustainability and spread that can support the systemic uptake (scale-up) of innovation.

If we take a broader view of the processes involved in the $3 \mathrm{~S}$ of healthcare innovations, there is consensus on the fundamental role of frequent monitoring and feedback. These mechanisms seem crucial for maintaining favourable stakeholder perception of the value and feasibility of the innovation over time. Less well-studied is the optimal balance between soft and hard metrics [77]. Use of quantitative data seems to support sustainability $[73,78,100]$. Use of monitoring and feedback for frequent reflection on the outcomes of innovation triggers a collective form of learning, which is associated with better chances of success in 3S [105]. Through collective learning, new collective cognitive products may lead to 


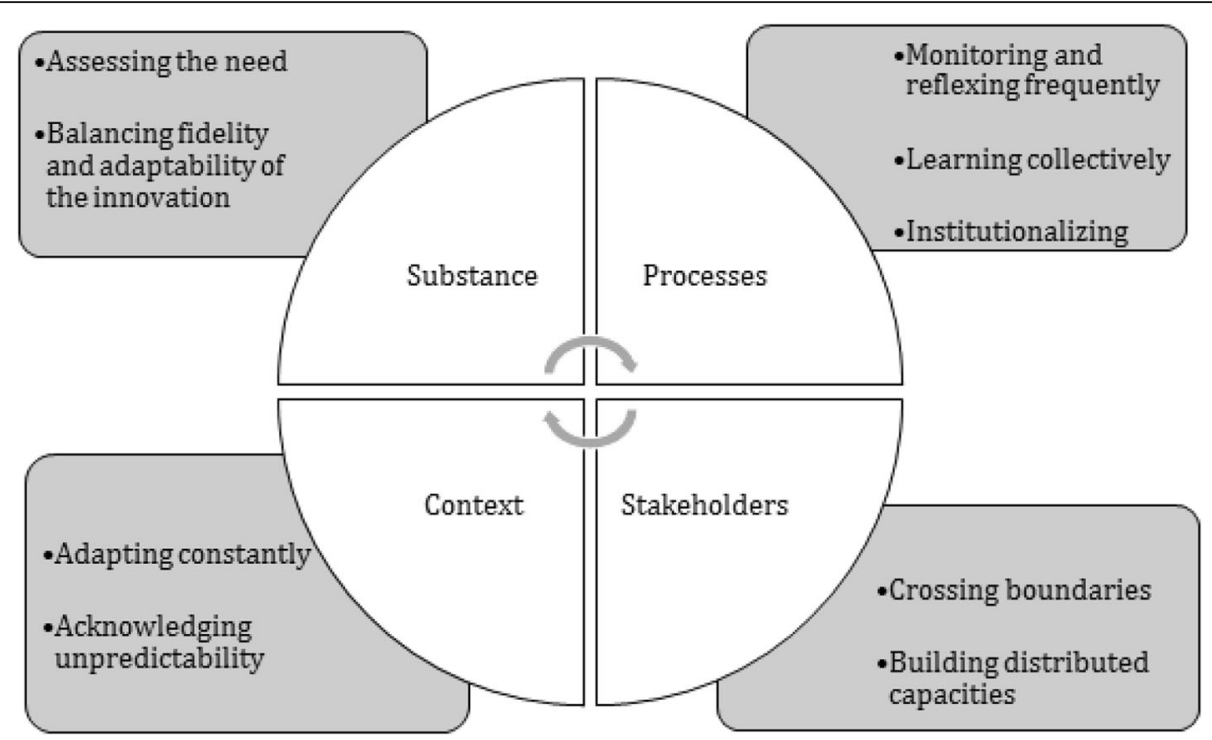

Fig. 2 Mechanisms involved in the 35 of healthcare innovations

behavioural changes that foster the institutionalisation of new values, beliefs, norms and organisational practices around the innovation $[65,105]$. This is particularly relevant for sustainability, as the innovation becomes an intrinsic part of the organisation or system's attitudes, norms, beliefs and behaviours.

Stakeholders The complexity of healthcare systems and stakeholders is both a barrier and facilitator to 3S. However, a paradox often appears, where the need to recognise and rely on distributed leadership to support the innovation journey arises in a context of interprofessional and interorganisational boundaries $[64,95,106]$. Consider the strong influence of the distribution of powers between the policy and delivery sides of healthcare systems, seen most obviously in structural hierarchies and accountability relationships [31, 107]. While this reality can sometimes limit the potential to $3 \mathrm{~S}$ innovations, it can also strengthen $3 \mathrm{~S}$ when stakeholders cross clinical, organisational, policy and jurisdictional boundaries to create distributed forms of agency [12, 74, 94]. Crossing boundaries increases the scope of capacitybuilding needed to support and operationalise 3S, fostering continuous improvement in healthcare within and across jurisdictions [108].

Context According to renowned healthcare improvement expert Berwick, "Researchers who wish to understand how improvement works, and why and when it fails, will never succeed if they regard context as experimental noise and the control of context as a useful design principle" [96, 97]. In line with Roger's theoretical take (DIM) on the social nature of diffusing innovations, as well as Shaw et al.'s idea of looking at the $3 \mathrm{~S}$ of innovation as social practices, Berwick highlights the need to recognise context as an active social ingredient in 3S [109]. The evolution of context itself may bring alignment between adaptation of the innovation and organisational needs and capacities. Though demanding, stakeholders must acknowledge and capitalise on the unpredictability of context, and its influence on the $3 S$ journey $[1,24,25]$, to assure that the innovation remains seen as credible, valuable and feasible. Indeed, the success of $3 \mathrm{~S}$ is dependant on an understanding of context, whether at the individual level, or as manifest in structural elements such as governance, resources, incentives, and accountability or regulations.

\section{Enablers and barriers}

There is no consensus on the 'right' combination of enabling conditions for the $3 \mathrm{~S}$ of healthcare innovations [75], and little evidence on when, during the $3 \mathrm{~S}$ journey, they should be mobilised. However, seven enabling factors emerged from our analysis as the most frequently identified and influential (Table 5). Of these, the two most important for potential innovation adopters within healthcare organisations or at the system level are the perceived value and feasibility of the innovation $[9,80,98$, $110,111]$. Indeed, perceptions are embedded in a complex web of other conditions, including the substance of the innovation, leadership, accountability, context, timing, management support and governance. However, a healthcare innovation appears more likely to spread, sustain and scale successfully if stakeholders shift their focus to recognise in these conditions the potential for new collaborations, the development of new capacities, and the empowerment of patients, 
Table 5 Support conditions of the 3S

\begin{tabular}{lll}
\hline Support conditions & Enabling & Limiting \\
\hline Substance (innovation) & Adaptable & Static \\
Leadership & Distributed & Hierarchical \\
Accountability & Reciprocal & Unilateral \\
Context & Absorptive & Tense \\
Timing and pace of change & Iterative & Linear \\
Management support & Empowering & Symbolic \\
Governance & Decentralised & Centralised \\
\hline
\end{tabular}

citizens and providers. New possibilities can emerge from collaborations within and across jurisdictions, a reciprocal mix of top-down, bottom-up and unconventional leadership, and protected time and space for learning, adapting and building innovation capacity $[12,13,15,24,25,64-67,69,70]$. We note a gap in evidence on the role of patients, families, citizens, third parties (e.g. research networks) and policy as enabling conditions to $3 \mathrm{~S}$.

\section{Discussion}

In this paper, we review scientific and grey literature evidence on the $3 \mathrm{~S}$ of healthcare innovations to better understand how they work as well as the mechanisms and conditions that either facilitate or hinder 3S. Health systems, supported by various agencies, are paying increasing attention to the problem of the $3 \mathrm{~S}$ of innovations [13, 18, 81, 84]. While they are not always well supported by evidence or applied appropriately, processes of $3 \mathrm{~S}$ are powerful engines to propagate these types of innovation. Health systems demonstrate much less capacity to support innovations in models of care or strategies to achieve large-scale improvements. We will look, in this section, at the policy and practical implications derived from analysis of the grey and scientific literature on how to spread, sustain and scale healthcare innovations from local settings to large-scale systems, focusing (1) on the why, (2) on perceived-value and feasibility, (3) on what people do, rather than what they should be doing, (4) on creating a dialogue between policy and delivery, and (5) on inclusivity and capacitybuilding. We embed these practical implications within a framework of actionable guidance for $3 \mathrm{~S}$ across five key focus areas (Fig. 3). This framework aims to encourage health system actors to focus on five main components of innovation journeys through the 3S. Our review of the literature finds that values, feasibility, capacity, inclusivity and learning are significant elements in the process of innovation in healthcare organisations. Our framework suggests that there is a complementary relationship between these elements. An integrated perspective that pays attention to each of these components would allow the emergence and identification of significant sources of change across innovation journeys in 3S, from delivery right through to policy. Our findings in this scoping review do not enable us to determine whether different degrees of attention are needed in processes of spread, sustainability and scale. However, given the dynamic, non-linear and sometimes overlapping journeys of the $3 \mathrm{~S}$ of innovation that can simultaneously cohabitate, we argue that it might be better to support an integrated focus on key elements that intersect and enrich all these processes, rather than invest efforts in trying to dissect their individual paths.

\section{Focus on the why}

An innovation is not an invention, and what is new to some organisations or practitioners may already be very familiar to others. An innovation will have different meanings for different people, which is something that should be valued. Meanings and values that emerge through 3S may challenge usual practices or reveal that an innovation is ill-suited to a given context and consequently result in its rejection. However, the evidence suggests that, if a sufficient number of individuals or organisations have adopted an innovation, it may successfully spread across a system [57]. Given the complexity, dynamism and plurality of healthcare institutions, it appears utopian to expect that the meaning of an innovation remains static over time [112]. Rather than try to propagate a standardised vision of an innovation within a given organisational setting or system, energies should focus on ensuring that everyone involved in or affected by the $3 \mathrm{~S}$ process can answer why they commit to the innovation; answers will not be the same for everyone [75]. Lags in momentum and interruptions are to be expected along the $3 \mathrm{~S}$ journey, but it is crucial that stakeholders consider that the innovation adds value to their work and to the quality of care and services they provide to patients [25]. As found by the NHS Scotland Quality Improvement Hub, "focussing on the why" ([94], p. 4) involves efforts such as sharing evidence on the relative advantage of the innovation, highlighting promising experiences from other jurisdictions, and monitoring and measuring performance to see improvement.

\section{Focus on perceived value and feasibility}

Innovation is always, to some degree, disruptive [113]. Innovation demands changes in the usual ways of doing things in an organisation or system [114, 115]. We call the efforts to spread, sustain and scale-up innovations 'innovation work' to reflect the emotional and behavioural adjustments potential users must make to put an innovation into practice. Further, adjustments reach beyond the level of individual adopters. The implementation of a new model of care requires changes in the roles 


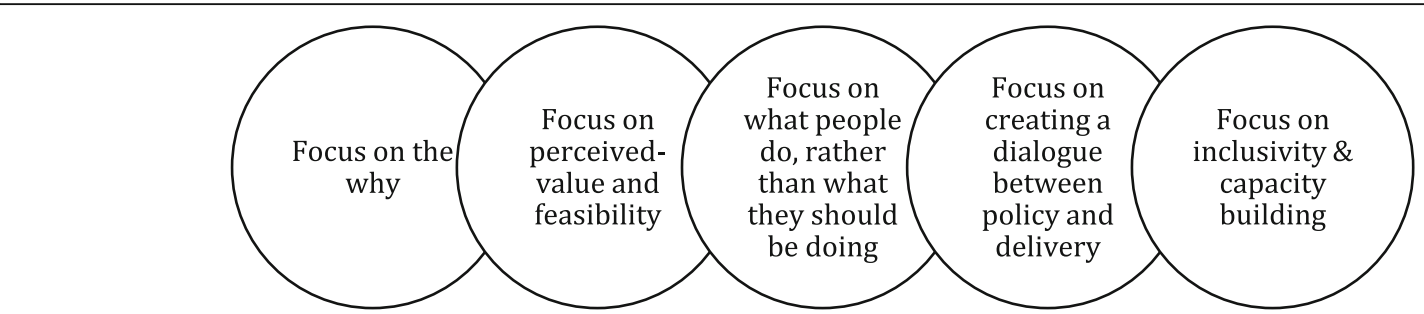

Fig. 3 Framework of actionable guidance for 35 across five key focus areas

of professional groups, in the relationships between providers from various sectors, in the financing of care, in regulations and labour contracts, and in the politics that shape care delivery [116]. Any significant innovation is a source of destabilisation and change for practice settings, and requires commitment from influential leaders and the development of policies to promote alignment between attributes of the innovation and existing regulations, thereby mitigating the negative effects of change [34]. Innovation work can be facilitated by support from influential leaders and by policies that promote alignment between the characteristics of the innovation and system functioning and regulations [104, 116]. Given the effort and energy required, the focus of $3 \mathrm{~S}$ must be on the perceived value and feasibility of innovations for health system actors. Efforts deliberately engaged by organisational actors, especially in disruptive contexts, are significantly motivated by the value they intend to create. The value pursued by health system actors may refer to the 'quadruple aim' of improvements in patient experience, population health and the well-being of healthcare teams, along with reductions in cost. However, as discussed earlier in this paper, value can be decontextualised by individuals into what they intrinsically aim to create or maximise for users, families, citizens, colleagues, etc. In highly pluralistic environments such as healthcare organisations, the feasibility of the efforts innovations require appears as a powerful condition to generate and maintain common values among actors. The belief in people that they are equipped and able to contribute to $3 \mathrm{~S}$ is crucial to maintaining motivation over time [64, 117-120]. Supporting and guiding collective action towards common goals throughout the innovation journeys requires the agility to create complementarities among stakeholders, even as each seeks to bring value to their own work and reinforce each other's competencies to achieve value.

\section{Focus on what people do, rather than what they should be doing}

Politicians and policy-makers are often impatient to see change and improvement in health systems [104]. They design and adopt policy reforms that often, from the point of view of healthcare providers, involve a wide range of innovations. Providers often must learn to work and collaborate differently to make innovation a reality in their practice setting. They need support to learn new ways of organising work and delivering care. Innovations are not adopted by reorganising people and rules to support, sustain and eventually spread and scale them up. Rather, innovation will become routine practice if providers have time to incorporate new practices into their local context, learning as they do so, and designing an approach that fits well with local needs and capacities [65]. This is one of the more delicate balances to manage in healthcare innovation - the need to leave space for local adaptation and the risk of diluting the strengths of the innovation $[1,121,122]$. It is not realistic to expect managers and policy-makers to support an open agenda for 3S, nor for providers to maintain motivation and commitment without incentives, especially when the innovation's benefits in improving patients' health status and care experience is unclear. However, forcing innovation work within a short-term agenda might hinder its potential sustainability [1]. The focus must therefore be on what people do, rather than what they should be doing. One strategy is to adopt management tools that continuously monitor and provide feedback on the ongoing work accomplished by stakeholders, rather than management tools that aim to increase control and coercion over expected work [123]. The more an innovation circulates across a variety of settings and contexts, the more it - and the stakeholders involved - will change [124]. Focussing on what people do, rather than on what they should do, helps to identify the sources of value and issues of feasibility in innovation work. Moreover, this allows us to situate the value and feasibility of innovation in a mechanism to assess and monitor the innovation process, which creates and protects room for adaptation in the innovation, in people and in the system.

Focus on creating a dialogue between delivery and policy There is growing recognition of the importance of context in shaping the destiny of innovation. Context is a multi-faceted concept. It can refer to broader policy and political context, and to more micro organisational or clinical contexts. The more diverse the contexts (political, organisational, clinical) an innovation touches, the 
more it will demand exchanges among a variety of actors [125]. An innovation will navigate these interlinked contexts along its journey from delivery to policy, or from policy to delivery [97]. For example, propagation of a new model of primary care may be influenced by negotiations between medical associations and government. To accommodate the multiplicity of contexts and forms of knowledge in the innovation journey, delivery and policy actors will establish a dialogue to arrive at common views of challenges and opportunities. Facilitating an innovation journey requires more than discussions across groups or organisations. This part of innovation work is essentially relational - the aim is for stakeholders to negotiate a way to move an innovation forward that will take their values and interests into account. Strategies to integrate the values and interests of a wide array of stakeholders may include forums and seminars that enable dialogue and problem solving, as well as informal opportunities for communication and deliberation between actors from all levels, from delivery to policy, who may have different views and interests. Champions of an innovation are often seen as facilitators to bridge the various groups affected by the propagation of an innovation, but let's think outside the box. Evidence points to benefits from distributed and unconventional (e.g. medical secretaries, support staff, patients and citizens) forms of leadership around the $3 \mathrm{~S}$ of innovation in healthcare [71]. While there are challenges associated with distributed leadership, such as shared decision-making and governance capacities, the presence of genuine experimenters is crucial to accelerate the impact of the $3 S$ of innovation [106, 126]. Dialogue between delivery and policy bodies during innovation journeys (3S) is a significant condition for increasing value, bringing coherence and creating complementarities among parts of healthcare systems that may challenge the penetration of new ways of thinking and doing.

\section{Focus on inclusivity and capacity-building}

Health systems are driven by the views, values and interests of multiple professional groups and organisations. In such an environment, it is difficult to promote an innovation by decree [127]. The risk of inertia is high and the propagation of innovations that challenge the status quo is slow. Innovations that are minimally or potentially disruptive will be adopted in health systems if they can challenge this inertia. There is a political economy inherent to health systems, and innovations that affect the allocation and circulation of resources or challenge the position of powerful groups will require explicit discussion and strategies to move forward [112]. The focus must therefore be on fostering distributed governance capacities. The involvement of new actors, such as citizens in health policy and patients in the design of care, may provide a strategy for moving forward. However, this may be insufficient on its own - multiple levers for large-scale transformation and improvement are needed. Countervailing powers, such as evidence of the pay-off of innovations, comparison between current practice and the proposed innovation, monitoring and measurement of performance gaps in the system, and dissemination of promising experience in other health systems, may help to challenge the status quo.

\section{Strengths and limitations}

This study has several strengths and limitations. In terms of strengths, it offers a timely and unique contribution by presenting the state of knowledge, reflected in peer-reviewed and grey literature from various jurisdictions and using a wide range of study designs and methodologies, on how to facilitate the $3 \mathrm{~S}$ of healthcare innovations. The study used a transparent, rigorous and replicable review process, and was developed collaboratively by researchers and decision-makers (CFHI). It contributes to filling current gaps by providing conceptual and operational guidance to support the spread, sustainability and scale of healthcare innovations within complex policy environments. However, our study presents some limitations. First, the scoping review design did not involve assessing the quality of included papers. Second, given the lack of methodological standards for scoping review designs, some scholars may disagree with our review process, which was supported by Booth's methodological approach [128]. Lastly, the framework of actionable guidance for $3 \mathrm{~S}$ across five key focus areas suggested in this paper has not yet undergone empirical validation. Future research should explore and validate the empirical application of the framework to better understand how to facilitate the $3 \mathrm{~S}$ of healthcare innovations.

\section{Conclusion}

Our review makes it clear that innovation is not a discrete event, but truly a journey. It encourages us to think of innovations as unpredictable and contextualised, which may therefore give rise to multiple journeys that interact and overlap over the course of the 3S. We have summarised five key lessons that can inform the experience of clinicians, managers, policy-makers, patients and citizens with innovations in health systems and, more importantly, can support their actions. These five lessons may constitute the ingredients for what we call 'innovation work' in health systems. The paper's main contribution, in looking at existing work of the $3 \mathrm{~S}$ of healthcare innovations, is a comprehensive view of the definitions, mechanisms and support conditions involved in 3S. Further research could look more closely at the role of regulations and legislation in the governance of 
spreading, sustaining and scaling-up healthcare innovations. Integrating research knowledge around policy capacities and innovation may be helpful. Moreover, while we recognise that theoretical contributions have been made to the field of innovation research applied to healthcare contexts, we argue that there is a need for greater consensus on the theoretical definition of what the $3 \mathrm{~S}$ are and how they proceed. The current consensus gap jeopardises the production of generative empirical studies, leaving scholars to study this process with only fragmented theoretical insights. We invite researchers to pay greater attention to unsuccessful experiences with the $3 \mathrm{~S}$ of healthcare innovations, which could help to elucidate the challenges involved and lessons learned to inform future initiatives. We consider that further empirical research could adopt realistic evaluation designs in order to uncover the generative mechanisms that expose how innovations are understood to work, by whom and in which circumstances through the unpredictable journeys of spreading, sustaining and scaling [129]. Moreover, realist evaluation could provide theoretical contributions by generating middle-range theories around the $3 \mathrm{~S}$ of healthcare innovations.

\section{Abbreviations}

3S: spread, sustainability, scale; CFHI: Canadian Foundation for Healthcare Improvement; DIM: Diffusion of Innovations Model; NHS: National Health Service; NPT: Normalisation Process Theory

\section{Acknowledgements}

The authors would like to thank Jennifer Verma for commissioning this work on behalf of the CFHI. Her leadership and support was vital to conducting and validating our methodological steps and results. We also thank the Acute Care for Elders (ACE) Collaborative Team from CFHI for their collaboration in the early stage of the research process.

\section{Authors' contributions}

$E ́ C B$ and JLD co-developed the methodological design and the search strategy for the scoping review. ÉCB conducted the search, screened ( $n=614)$ and selected $(n=24)$ the relevant papers, extracted and synthesised the data from included papers, and wrote the article (including figures and tables). $J L D$ validated the paper selection, the data extraction and analysis process, co-wrote the introduction, led the writing of the discussion section, and revised the article drafts. Alongside stakeholders from the Canadian Foundation for Healthcare Improvement (CFHI) validating each step of the review process, BC and MS participated in data synthesis, revision and editing of the manuscript. All authors read and approved the final article.

\section{Funding}

This study was commissioned and funded by the Canadian Foundation for Healthcare Improvement (CFHI), from October 2016 to October 2017. Stakeholders from the funding body (CFHI) were involved in the data synthesis of the review, the validation of interpretation of data, and the revision and editing of the writing of the manuscript. The funding body (CFHI) was not involved in the design of the study nor the writing of the manuscript per se.

\section{Availability of data and materials}

All data generated or analysed during this study are included in this published article.

Ethics approval and consent to participate Not applicable.
Consent for publication

Not applicable.

\section{Competing interests}

The authors declare that they have no competing interests.

\section{Author details}

${ }^{1}$ Health Sciences Research, Faculty of Medicine and Health Sciences, University of Sherbrooke, Quebec, Canada. ${ }^{2}$ Charles-Le Moyne - SaguenayLac-Saint-Jean Research Center on Health Innovations, Quebec, Canada. ${ }^{3}$ Doctoral Award Fellow from Quebec's Fonds de recherche du Québec Santé (FRQS), Quebec, Canada. ${ }^{4}$ Health Standards Organization, Ottawa, Canada. ${ }^{5}$ Health Administration Department, School of Public Health, University of Montreal, Quebec, Canada. ${ }^{6}$ University of Montreal Hospital Research Center, Quebec, Canada. ${ }^{7}$ Canada Research Chair (Tier I) holder on Health system design and adaptation (Canadian Institutes of Health Research), Montreal, Canada. ${ }^{8}$ Canadian Foundation for Healthcare Improvement, Corporate Strategy and Program Development, Ottawa, Canada.

Received: 13 March 2019 Accepted: 1 August 2019

Published online: 13 September 2019

\section{References}

1. Fitzgerald L, McDermott A. Challenging Perspectives on Organizational Change in Health Care, vol. 3. New York, NY: Taylor \& Francis; 2017.

2. Atun R. Health systems, systems thinking and innovation. Health Policy Plan. 2012;27(Suppl 4):iv4-8

3. Herzlinger RE. Why innovation in health care is so hard. Harv Bus Rev. 2006; 84(5):58.

4. Paina L, Peters DH. Understanding pathways for scaling up health services through the lens of complex adaptive systems. Health Policy Plan. 2012; 27(5):365-73.

5. Aher K, Luoma-Aho V. Contextualising Change in Public Sector Organisations. In: How Strategic Communication Shapes Value and Innovation in Society (Advances in Public Relations and Communication Management, Vol. 2): Emerald Publishing Limited; 2017. p. 23-35. https:// doi.org/10.1108/S2398-391420170000002002.

6. Naylor D, Girard F, Mintz J, Fraser N, Jenkins T, Power C. Unleashing Innovation: Excellent Healthcare for Canada. Report of the Advisory Panel on Healthcare Innovation; 2015. http://healthycanadians.gc.ca/publications/ health-system-systeme-sante/report-healthcare-innovation-rapport-soins/alt/ report-healthcare-innovation-rapport-soins-eng.pdf. Accessed 1 Sept 2019.

7. Health Quality Ontario. Quality Improvement Primers: Spread Primer. Queens, Ontario: Health Quality Ontario; 2013.

8. Velthoven V, Helena M, Cordon C. Sustainable Adoption of Digital Health Innovations: Perspectives From a Stakeholder Workshop. J Med Internet Res. 2019;21(3):e11922

9. Charif $A B$, Zomahoun HTV, LeBlanc A, Langlois L, Wolfenden L, Yoong SL, et al. Effective strategies for scaling up evidence-based practices in primary care: a systematic review. Implement Sci. 2017;12(1):139.

10. Best A, Greenhalgh T, Lewis S, Saul JE, Carroll S, Bitz J. Large-system transformation in health care: a realist review. Milbank Q. 2012;90(3):421-56.

11. Perla RJ, Bradbury E, Gunther-Murphy C. Large-scale improvement initiatives in healthcare: a scan of the literature. J Healthc Qual. 2013;35(1):30-40.

12. Shaw J, Shaw S, Wherton J, Hughes G, Greenhalgh T. Studying scale-up and spread as social practice: theoretical introduction and empirical case study. J Med Internet Res. 2017;19(7):e244.

13. Greenhalgh T, Wherton J, Papoutsi C, Lynch J, Hughes G, A'Court C, et al. Beyond adoption: a new framework for theorizing and evaluating nonadoption, abandonment, and challenges to the scale-up, spread, and sustainability of health and care technologies. J Med Internet Res. 2017; 19(11):e367.

14. Sibthorpe BM, Glasgow NJ, Wells RW. Emergent themes in the sustainability of primary health care innovation. Med J Aust. 2005;183(10):S77.

15. Slaghuis SS. Riding the Waves of Quality Improvement: Sustainability and Spread in a Dutch Quality Improvement Program for Long-Term Care [PhD Thesis]. Rotterdam: Erasmus MC: University Medical Center; 2016.

16. Øvretveit J, Garofalo L, Mittman B. Scaling up improvements more quickly and effectively. Int J Qual Health Care. 2017;29(8):1014-9. 
17. Van de Ven AH, Polley DE, Garud R, Venkataraman S. The Innovation Journey. New York: Oxford University Press; 1999.

18. Damanpour F, Gopalakrishnan S. Theories of organizational structure and innovation adoption: the role of environmental change. J Eng Techno Manag. 1998;15(1):1-24.

19. Bekkers V, Edelenbos J, Nederhand J, Steijn AJ, Tummers LG, Voorberg WH. The Social Innovation Perspective in the Public Sector: Co-creation, Selforganization and Meta-governance. 2014. https://dspace.library.uu.nl/ handle/1874/354552. Accessed 1 Sept 2019.

20. Davies R, Harty C. Building Information Modelling as Innovation Journey: BIM Experiences on a Major UK Healthcare Infrastructure Project. In: 6th Nordic Conference on Construction Economics and Organisation-Shaping the Construction/Society Nexus; 2011. http://www.irbnet.de/daten/iconda/ CIB21370.pdf. Accessed 1 Sept 2019.

21. Fitzgerald L, Ferlie $E$, Wood M, Hawkins C. Interlocking interactions, the diffusion of innovations in health care. Hum Relat. 2002;55(12):1429-49.

22. Valente TW, Rogers EM. The origins and development of the diffusion of innovations paradigm as an example of scientific growth. Sci Commun. 1995;16(3):242-73.

23. Chandler J, Rycroft-Malone J, Hawkes C, Noyes J. Application of simplified complexity theory concepts for healthcare social systems to explain the implementation of evidence into practice. J Adv Nurs. 2016;72(2):461-80

24. Lanham HJ, Leykum LK, Taylor BS, McCannon CJ, Lindberg C, Lester RT. How complexity science can inform scale-up and spread in health care: understanding the role of self-organization in variation across local contexts. Soc Sci Med. 2013:93:194-202.

25. Buchanan DA, Fitzgerald L, Ketley D. The Sustainability and Spread of Organizational Change: Modernizing Healthcare. Abingdon: Routledge; 2006.

26. Dalitz $R$, Holmén $M$, Scott-Kemmis D. How do innovation systems interact? Schumpeterian innovation in seven Australian sectors. Prometheus. 2012; 30(3):261-89.

27. Barnett J, Vasileiou K, Djemil F, Brooks L, Young T. Understanding innovators' experiences of barriers and facilitators in implementation and diffusion of healthcare service innovations: a qualitative study. BMC Health Serv Res. 2011;11(1):1.

28. Djellal F, Gallouj F. Mapping innovation dynamics in hospitals. Res Policy. 2005;34(6):817-35.

29. May C, Finch T, Mair F, Ballini L, Dowrick C, Eccles M, et al. Understanding the implementation of complex interventions in health care: the normalization process model. BMC Health Serv Res. 2007;7(1):148.

30. Chandler AD Jr. The Visible Hand: The Managerial Revolution in American Business. Cambridge: Harvard University Press; 1993.

31. Johnson SB, Marrero D. Innovations in healthcare delivery and policy: Implications for the role of the psychologist in preventing and treating diabetes. Am Psychol. 2016;71(7):628.

32. May C. Agency and implementation: understanding the embedding of healthcare innovations in practice. Soc Sci Med. 2013;78:26-33.

33. Nicholls A, Murdock A. Social Innovation: Blurring Boundaries to Reconfigure Markets. Basingstoke: Palgrave Macmillan; 2011.

34. Denis J-L, Hébert $Y$, Langley A, Lozeau D, Trottier L-H. Explaining diffusion patterns for complex health care innovations. Health Care Manag Rev. 2002; 27(3):60-73.

35. Dougherty D. Bridging social constraint and social action to design organizations for innovation. Organ Stud. 2008;29(3):415-34.

36. Rogers EM. Diffusion of Innovations. New York: Free Press; 1995. p. 12.

37. Proctor E, Luke D, Calhoun A, McMillen C, Brownson R, McCrary S, et al. Sustainability of evidence-based healthcare: research agenda, methodological advances, and infrastructure support. Implement Sci. 2015; 10(1):88

38. Elzen B, Geels FW, Green K. System Innovation and the Transition to Sustainability: Theory, Evidence and Policy. Cheltenham: Edward Elgar Publishing; 2004

39. Denis J-L, Forest P-G. Real reform begins within: an organizational approach to health care reform. J Health Polit Policy Law. 2012;37(4):633-45.

40. Denis J-L. Pathways to transformation in publicly-funded health systems: experience in Canada's provinces. Can Success Stories Health Soc Care. 2018;11.

41. Denis J-L, Usher S, Baker GR, Côté-Boileau É, Normandin JM. Transcending the Paradigm Freeze: Narratives of Reform in Canadian Health Systems. Copenhagen: 33rd European Group for Organizational Studies Colloquium; 2017.
42. Coiera E. Why system inertia makes health reform so difficult. BMJ. 2011;342: d3693.

43. Lazar H, Forest P-G, Church J, Lavis JN. Paradigm Freeze: Why it is so Hard to Reform Health Care in Canada. Montreal: McGill-Queen's Press; 2013.

44. Reeves S, Pelone F, Harrison R, Goldman J, Zwarenstein M. Interprofessional collaboration to improve professional practice and healthcare outcomes. Cochrane Database Syst Rev. 2017;6:CD000072.

45. Kaplan HC, Provost LP, Froehle CM, Margolis PA. The Model for Understanding Success in Quality (MUSIQ): building a theory of context in healthcare quality improvement. BMJ Qual Saf. 2012;21(1): $13-20$.

46. Series B, Kilo CM. A framework for collaborative improvement: lessons from the institute for healthcare improvement's breakthrough series. Qual Manag Health Care. 1998;6(4):1-13.

47. Mittman BS. Creating the evidence base for quality improvement collaboratives. Ann Intern Med. 2004;140(11):897-901.

48. Schouten LM, Hulscher ME, van Everdingen JJ, Huijsman R, Grol RP. Evidence for the impact of quality improvement collaboratives: systematic review. BMJ. 2008;336(7659):1491-4.

49. Howe C, Randall K, Chalkley S, Bell D. Supporting improvement in a quality collaborative. Br J Healthc Manag. 2013:19(9):434-42.

50. Thor J. Getting Going on Getting Better: How is Systematic Quality Improvement Established in a Healthcare Organization?: Implications for Change Management Theory and Practice. Stockholm: Institutionen för lärande, informatik, management och etik, LIME/Department of Learning, Informatics, Management and Ethics (Lime); 2007.

51. Denis J-L, Davies HTO, Ferlie E, Fitzgerald L. Assessing Initiatives to Transform Healthcare Systems: Lessons for the Canadian Healthcare System. Ottawa: Canadian Foundation for Healthcare Improvement; 2011.

52. Hartmann CW, Palmer JA, Mills WL, Pimentel CB, Allen RS, Wewiorski NJ, et al. Adaptation of a nursing home culture change research instrument for frontline staff quality improvement use. Psychol Serv. 2017;14(3):337.

53. Kislov R, Humphreys J, Harvey G. How do managerial techniques evolve over time? The distortion of "facilitation" in healthcare service improvement. Public Manag Rev. 2017;19(8):1165-83.

54. Donetto S, Pierri P, Tsianakas V, Robert G. Experience-based co-design and healthcare improvement: realizing participatory design in the public sector. Des J. 2015;18(2):227-48.

55. Voorberg WH, Bekkers VJ, Tummers LG. A systematic review of co-creation and co-production: embarking on the social innovation journey. Public Manag Rev. 2015;17(9):1333-57.

56. Rogers EM. A prospective and retrospective look at the diffusion model. J Health Commun. 2004;9(S1):13-9.

57. Rogers EM. Diffusion of Innovations. New York: Simon and Schuster; 2010.

58. Rogers EM, Medina UE, Rivera MA, Wiley CJ. Complex adaptive systems and the diffusion of innovations. Innov J. 2005;10(3):1-26.

59. Rogers EM. Diffusion of Innovations: Modifications of a Model for Telecommunications. In: Die Diffusion von Innovationen in der Telekommunikation: Springer; 1995. p. 25-38.

60. Booth A, Sutton A, Papaioannou D. Systematic Approaches to a Successful Literature Review. London: Sage; 2016.

61. May CR, Mair F, Finch T, MacFarlane A, Dowrick C, Treweek S, et al. Development of a theory of implementation and integration: Normalization Process Theory. Implement Sci. 2009;4(1):29.

62. Pye A, Pettigrew A. Studying board context, process and dynamics: some challenges for the future. Br J Manag. 2005;16(s1). https://doi.org/10.1111/ j.1467-8551.2005.00445.x.

63. Greenhalgh T, Robert G, Macfarlane F, Bate P, Kyriakidou O. Diffusion of innovations in service organizations: systematic review and recommendations. Milbank Q. 2004;82(4):581-629.

64. Ferlie E, Fitzgerald L, Wood M, Hawkins C. The nonspread of innovations: the mediating role of professionals. Acad Manag J. 2005;48(1):117-34.

65. Slaghuis SS, Strating MM, Bal RA, Nieboer AP. A framework and a measurement instrument for sustainability of work practices in long-term care. BMC Health Serv Res. 2011;11(1):314.

66. Norton WE, McCannon CJ, Schall MW, Mittman BS. A stakeholder-driven agenda for advancing the science and practice of scale-up and spread in health. Implement Sci. 2012;7(1):118.

67. Ploeg J, Markle-Reid M, Davies B, Higuchi K, Gifford W, Bajnok I, et al. Spreading and sustaining best practices for home care of older adults: a grounded theory study. Implement Sci. 2014;9(1):162. 
68. Brewster AL, Curry LA, Cherlin EJ, Talbert-Slagle K, Horwitz LI, Bradley EH. Integrating new practices: a qualitative study of how hospital innovations become routine. Implement Sci. 2015;10:168.

69. Milat AJ, Newson R, King L, Rissel C, Wolfenden L, Bauman A, et al. A guide to scaling up population health interventions. Public Health Res Pract. 2016; 26(1):e2611604.

70. Gupta A, Thorpe C, Bhattacharyya O, Zwarenstein M. Promoting development and uptake of health innovations: The Nose to Tail Tool. F1000Res. 2016;5:361.

71. Lennox L, Doyle C, Reed JE, Bell D. What makes a sustainability tool valuable, practical and useful in real-world healthcare practice? A mixed methods study on the development of the Long Term Success Tool in Northwest London. BMJ Open. 2017;7(9):e014417.

72. Massoud MR, Nielsen GA, Nolan K, Schall MW, Sevin C. A Framework for Spread: From Local Improvements to System-Wide Change. In: IHI Innovation Series white paper. Cambridge, MA: Institute for Healthcare Improvement; 2006.

73. Clinical Excellence Commission. Enhancing Project Spread and Sustainability - A Companion to the 'Easy Guide to Clinical Practice Improvement'. Sydney: CEC; 2008.

74. Lomas J. Formalised Informality: An Action Plan to Spread Proven Health Innovations: New Zealand Ministry of Health; 2008. https://www.health.govt. nz/system/files/documents/publications/formalised-informality-v2-jan08.pdf. Accessed 1 Sept 2019

75. NHS Scotland Quality Improvement Hub. The Spread and Sustainability of Quality Improvement in Healthcare: A Resource to Increase Understanding of the 10 Key Factors Underpinning Successful Spread and Sustainability of Quality Improvement in NHS Scotland. 2014. http://www.qihub.scot.nhs.uk/ media/596811/the\%20spread\%20and\%20sustainability\%20ofquality\%2 Oimprovement\%20in\%20healthcare\%20pdf\%20.pdf. Accessed 1 Sept 2019.

76. Healthcare Improvement Scotland. Guide to Spread and Sustainability. http://www.healthcareimprovementscotland.org/about_us/what_we_do/ knowledge_management/knowledge_management_resources/spread_ and_sustainability.aspx. Accessed 27 Aug 2019.

77. What Works Scotland. What Works Scotland Evidence Review: Scaling-Up Innovations. 2015. http://whatworksscotland.ac.uk/wp-content/uploads/2 015/06/WWS-EB-evidence-review-Scaling-Up-Innovations-June-2015.pdf. Accessed 1 Sept 2019.

78. NHS Institute for Innovation and Improvement. Sustainability Model and Guide. 2013. https:/www.england.nhs.uk/improvement-hub/wp-content/uploads/ sites/44/2017/11/NHS-Sustainability-Model-2010.pdf. Accessed 1 Sept 2019.

79. Gabriel M. Making It Big: Strategies for Scaling Social Innovations: Nesta; 2014. https://media.nesta.org.uk/documents/making_it_big-web.pdf. Accessed 1 Sept 2019.

80. Milat AJ, Bauman A, Redman S. Narrative review of models and success factors for scaling up public health interventions. Implement Sci. 2015;10(1):113.

81. Plsek P. Complexity and the adoption of innovation in health care. Accelerating Quality Improvement in Health Care: Strategies to Accelerate the Diffusion of Evidence-Based Innovations. Washington, DC: Nationa Institute for Healthcare Management Foundation and National Committee for Quality in Health Care; 2003.

82. Chaudoir SR, Dugan AG, Barr CH. Measuring factors affecting implementation of health innovations: a systematic review of structural, organizational, provider, patient, and innovation level measures. Implement Sci. 2013:8(1):22.

83. Mangham $L$, Hanson K. Scaling up in international health: what are the key issues? Health Policy Plan. 2010;25(2):85-96.

84. Milat AJ, King L, Bauman AE, Redman S. The concept of scalability: increasing the scale and potential adoption of health promotion interventions into policy and practice. Health Promot Int. 2012;28(3):285-29.

85. Card JJ, Solomon J, Cunningham SD. How to adapt effective programs for use in new contexts. Health Promot Pract. 2011;12(1):25-35.

86. Kilbourne AM, Neumann MS, Pincus HA, Bauer MS, Stall R. Implementing evidence-based interventions in health care: application of the replicating effective programs framework. Implement Sci. 2007;2(1):42.

87. McDermott AM, Kitchener M, Exworthy M. Managing Improvement in Healthcare: Attaining, Sustaining and Spreading Quality. Basingstoke: Palgrave Macmillan; 2017.

88. Ilott I, Gerrish K, Pownall S, Eltringham S, Booth A. Exploring scale-up, spread, and sustainability: an instrumental case study tracing an innovation to enhance dysphagia care. Implement Sci. 2013;8(1):128.
89. Barker PM, Reid A, Schall MW. A framework for scaling up health interventions: lessons from large-scale improvement initiatives in Africa. Implement Sci. 2016;11(1):12.

90. Edwards N. Scaling-up Health Innovations and Interventions in Public Health: A Brief Review of the Current State-of-the-Science; 2010. p. 145. http://scholar.google.com/scholar_url?url=http\%3A\%2F\%2Fwww.ihi. org\%2Feducation\%2FDocuments\%2FProgramMaterials\%2 FScaleUpBlog\%2F7a_Commissioned_Paper\%25202_Public_Health. $\mathrm{doc} \& \mathrm{hl}=\mathrm{fr} \& \mathrm{sa}=\mathrm{T} \& \mathrm{o}=\mathrm{g} g a \& c t=\mathrm{gga} \& \mathrm{~cd}=0 \& \mathrm{~d}=6900197457064837426 \& \mathrm{e}=$ BdlnXdCEJYOAywTs3Lr4Dg\&scisig=AAGBfm3Q32oKoRhWvjh1bLn-bvO5 nXFIKw\&noss|=1\&ws=1366x643\&at=Scaling-up\%20health\%2 Oinnovations\%20and\%20interventions\%20in\%20public\%20health\%3A\%2 0a\%20brief\%20review\%20of\%20the\%20current\%20state-of-the-science. Accessed 1 Sept 2019

91. Greenhalgh T, Robert G, Macfarlane F, Bate P, Kyriakidou O, Peacock R. Storylines of research in diffusion of innovation: a meta-narrative approach to systematic review. Soc Sci Med. 2005;61(2):417-30.

92. Massoud M, Donohue K, McCannon C. Options for Large-scale Spread of Simple High-impact Interventions. 2010. USAID Health Care Improvement Project/URC. https://www.usaidassist.org/sites/default/files/options_for_ large-scale_spread_of_simple_high-impact_interventions_sept10_0.pdf. Accessed 1 Sept 2019

93. Canadian Foundation for Healthcare Improvement. The Canadian Foundation for Healthcare Improvement Spread Plan. 2014. https://www. cfhi-fcass.ca/sf-docs/default-source/work-with-us/4june2014-spreadplan. docx. Accessed 1 Sept 2019.

94. NHS Scotland Quality Improvement Hub. The Spread and Sustainability of Quality Improvement in Healthcare: A Practical Insight into Spreading and Sustaining Change in an Acute Clinical Setting. 2015. http://www.qihub.scot nhs.uk/media/835521/spread\%20and\%20sustainability\%20study\%2 Oreview\%20(web).pdf. Accessed 1 Sept 2019.

95. Sergi V, DENIS J, Langley A. Opening up perspectives on plural leadership. Ind Organ Psychol. 2012;5(4):403-7.

96. Bate P, Mendel P, Robert G. Organizing for Quality: The Improvement Journeys of Leading Hospitals in Europe and the United States. London: Radcliffe Publishing; 2008.

97. Fulop N, Robert G. Context for Successful Quality Improvement. London: The Health Foundation; 2015. https://www.health.org.uk/publications/ context-for-successful-quality-improvement. Accessed 1 Sept 2019

98. Lennox L, Maher L, Reed J. Navigating the sustainability landscape: a systematic review of sustainability approaches in healthcare. Implement Sci. 2018;13(1):27.

99. Millar R. Framing quality improvement tools and techniques in healthcare: the case of Improvement Leaders' Guides. J Health Organ Manag. 2013; 27(2):209-24.

100. Singh RK, Murty HR, Gupta SK, Dikshit AK. An overview of sustainability assessment methodologies. Ecol Indic. 2009;9(2):189-212.

101. Langley A. Strategies for theorizing from process data. Acad Manag Rev. 1999:24(4):691-710.

102. Langley A, Tsoukas H. The Sage Handbook of Process Organization Studies. London: Sage; 2016.

103. Langley A, Tsoukas $\mathrm{H}$. Introducing perspectives on process organization studies. Process Sensemaking Organizing. 2010;1(9):1-27.

104. Hardee K, Ashford L, Rottach E, Jolivet R, Kiesel R. The policy dimensions of scaling up health initiatives; 2012. https://www.healthpolicyproject.com/ pubs/83_ScaleupPolicyJuly.pdf. Accessed 1 Sept 2019.

105. Heikkila T, Gerlak AK. Building a conceptual approach to collective learning: lessons for public policy scholars. Policy Stud J. 2013;41(3):484-512.

106. Denis J-L, Langley A, Sergi V. Leadership in the plural. Acad Manag Ann. 2012:6(1):211-83.

107. Cairney P. Evidence-based best practice is more political than it looks: a case study of the 'Scottish Approach'. Evidence Policy. 2017;13(3):499-515.

108. Denis J-L. Taking Stock of Healthcare Reforms: A Reseach Program on Transformative Capacity of Healthcare Systems in Canada. Ottawa: Canadian Institutes of Health Research, Government of Canada; 2015

109. Dopson S, Fitzgerald L, Ferlie E. Understanding change and innovation in healthcare settings: reconceptualizing the active role of context. J Chang Manag. 2008;8(3-4):213-31.

110. Hayes C. The Highly Adaptable Improvement Model. Toronto: Acute Care for Elders (ACE) Collaborative Workshop, Canadian Foundation for Healthcare Improvement; 2016. 
111. Birken SA, DiMartino LD, Kirk MA, Lee S-YD, McClelland M, Albert NM. Elaborating on theory with middle managers' experience implementing healthcare innovations in practice. Implement Sci. 2015;11(1):2.

112. Alvehus J, Barbulescu R, Empson L, Gardner HK, Gibeau EM, King M, et al. Leading Professionals: Plurality, Process, and Power. In: Academy of Management Proceedings. New York: Academy of Management Briarcliff Manor; 2016.

113. Christensen CM, Raynor ME, McDonald R. What is disruptive innovation. Harvard Bus Rev. 2015;93(12):44-53.

114. Christensen CM, Overdorf M. Meeting the challenge of disruptive change. Harv Bus Rev. 2000;78(2):66-77.

115. Christensen CM, Bohmer R, Kenagy J. Will disruptive innovations cure health care? Harv Bus Rev. 2000;78(5):102-12.

116. Baker GR, Denis J-L. Medical leadership in health care systems: from professional authority to organizational leadership. Public Money Manag. 2011;31(5):355-62.

117. Baxter K, Weiss M, Le Grand J. The dynamics of commissioning across organisational and clinical boundaries. J Health Organ Manag. 2008;22(2): $111-28$.

118. Edenius M, Keller C, Lindblad S. Managing knowledge across boundaries in healthcare when innovation is desired. Knowledge Manag E-Learning. 2010; 2(2):134.

119. Fronek P, Kendall MB. The impact of Professional Boundaries for Health Professionals (PBHP) training on knowledge, comfort, experience, and ethical decision-making: a longitudinal randomized controlled trial. Disabil Rehabil. 2017:39(24):2522-9.

120. Håland E, Osmundsen TC. Establishing and sustaining collaboration across organizational boundaries within healthcare. Int J Integrated Care. 2015; 15(5). https://doi.org/10.5334/ijic.2076.

121. Egan M, Brennan A, Buykx P, De Vocht F, Gavens L, Grace D, et al. Local policies to tackle a national problem: Comparative qualitative case studies of an English local authority alcohol availability intervention. Health Place. 2016:41:11-8.

122. Burns L, Bradley E, Weiner B. Shortell and Kaluzny's Healthcare Management: Organization Design and Behavior. Boston: Cengage Learning; 2011.

123. Levesque J-F, Sutherland $\mathrm{K}$. What role does performance information play in securing improvement in healthcare? a conceptual framework for levers of change. BMJ Open. 2017;7(8):e014825.

124. Denis JL, Beaulieu MD, Hébert Y, Langley A, Lozeau D, Pineault R, Trottier LH. L'innovation clinico-organisationnelle dans les organisations de santé. Rapport au FCRSS. 2001. https://www.fcass-cfhi.ca/SearchResultsNews/01-0501/2795b7f5-30cb-4045-a1e8-72d7e08d8067.aspx. Accessed 1 Sept 2019.

125. Denis J-L, Lamothe L, Langley A. The dynamics of collective leadership and strategic change in pluralistic organizations. Acad Manag J. 2001; 44(4):809-37.

126. Kiefer L, Frank J, Di Ruggiero E, Dobbins M, Manuel D, Gully PR, et al. Fostering evidence-based decision-making in Canada: examining the need for a Canadian population and public health evidence centre and research network. Can J Public Health. 2005;96(3):11-19.

127. Denis J-L, Langley A, Cazale L, Denis J-L, Cazale L, Langley A. Leadership and strategic change under ambiguity. Organ Stud. 1996;17(4):673-99.

128. O'Brien KK, et al. Advancing scoping study methodology: a web-based survey and consultation of perceptions on terminology, definition and methodological steps. BMC Health Serv Res. 2016;16:305.

129. Pawson R, Tilley N. Realistic Evaluation. London: Sage; 1997.

\section{Publisher's Note}

Springer Nature remains neutral with regard to jurisdictional claims in published maps and institutional affiliations.

Ready to submit your research? Choose BMC and benefit from:

- fast, convenient online submission

- thorough peer review by experienced researchers in your field

- rapid publication on acceptance

- support for research data, including large and complex data types

- gold Open Access which fosters wider collaboration and increased citations

- maximum visibility for your research: over $100 \mathrm{M}$ website views per year

At $\mathrm{BMC}$, research is always in progress.

Learn more biomedcentral.com/submissions 